\title{
Covıd-19 Pandemi ve 2008 Ekonomik Kriz Dönemlerinde Riskten Kaçınma Düzeyinin ABD ve BRIC Piyasa Entegrasyonu Üzerindeki Değişen Etkisi*
}

\author{
Ecenur Uğurlu YILDIRIM**
}

\section{ÖZET}

Nakit akışına bağll olmayan faktörlerin ülkelerin finansal piyasalarının entegrasyonu üzerindeki etkileri literatürde en çok ilgi gören konulardan biridir. Son yüzyllın en büyük salgını olan COVID-19'un finans piyasalarına etkileri ise sicak tartışmaların odak noktası halindedir. Bu çalışmanın amacı, yatırımcıların zamanla değişen riskten kaçınma düzeylerindeki değişimin Amerika Birleşik Devletleri ve BRIC (Brezilya, Rusya, Hindistan ve Çin) hisse senedi piyasaları arasındaki entegrasyona COVID-19 salginı ve 2008 ekonomik krizi dönemindeki uzun ve kısa dönem asimetrik etkilerini incelemektir. Verilerin analizinde gecikmesi dağıtılmış doğrusal olmayan otoregresif model (NARDL) yönteminden yararlanılmıştır. Kısa vadede, tüm ülkeler için riskten kaçınma düzeyindeki olumlu değişimlerin entegrasyonu arttırdı̆̆ görülürken, olumsuz değişikliklerin korelasyonu azalttı̆̆ bulgusuna ulaşllmıştır. Üstelik bu etkinin pandemi döneminde, 2008 ekonomik krizine göre çok daha fazla ve istatistiksel olarak anlamlı olduğu bulunmuştur.

Anahtar Kelimeler: Riskten kaçınma, dinamik şartlı korelasyon, COVID-19

JEL Sinıflandırması: F15, F30

\section{The Changing Effect of the Risk Aversion on US And BRIC Market Integration} During The COVID 19 Pandemic and 2008 Economic Crisis

\section{ABSTRACT}

The effects of non-cash flow-related factors on the integration of countries' financial markets is one of the most debated topics in the literature. The effects of the COVID-19, the biggest pandemic of the last century, on the financial markets are the focus of hot discussions. The aim of this study is to examine the long and short-run asymmetric effects of the change in risk aversion of investors on the integration between the stock market of the United States (USA) and of BRIC (Brazil, India, Russia, and China) during the COVID-19 outbreak and the 2008 economic crisis. The nonlinear autoregressive distributed lag (NARDL) method is employed in this study. In the short-run, it is concluded that positive changes in risk aversion increase integration for all countries, while negative changes reduce correlation. Moreover, this effect is greater and more statistically significant during the pandemic period than the 2008 crisis.

Keywords: Risk aversion, dynamic conditional correlation, COVID-19

Jel Classification: F15, F30

\footnotetext{
* Makale Gönderim Tarihi: 22.01.2021, Makale Kabul Tarihi: 17.03.2021 , Makale Türü: Nicel Araştırma ** Dr. Öğr. Üyesi, Ankara Sosyal Bilimler Üniversitesi, ecenur.yildirim@asbu.edu.tr, ORCID: 0000-0001-64654781.
} 


\section{GíRiş}

Bireylerin belirsizlik zamanlarındaki karar alma mekanizmaları çok uzun yıllardır araştırmacıların üzerinde çalıştığı bir alandır. Riskin mevcut olduğu birçok durumda bireylerin ekonomik davranışlarına niteliksel açıklama sağlayan riskten kaçınma düzeyinin etkileri de özellikle yaşanan küresel ekonomik krizler sonrası tekrardan ilgilerin odağı haline gelmiş̧ir (Werner, 2008:1). Çalışmalar, olumsuz şoklarla ilişkili korkunun bireylerin risk alma isteklerini değiştirdiğini göstermiştir (bkz. Loewenstein, 2000:430; Knutson vd., 2008:512; Guiso vd., 2018:404). Bireylerin risk iştahlarının finansal pazarlardaki etkileri de literatürde üzerinde durulan bir konudur. Mevcut literatür, küresel varlık getirilerinin önemli bir kısmının, küresel riskten kaçınma düzeyi ile açıklanabildiği gösterilmiştir (bkz. MirandaAgrippino ve Rey, 2015:2; Xu, 2019:2). Yaşanan ekonomik krizler sonrası, hisse senedi piyasalarının entegrasyonu pek çok çalışmaya konu olmuş ve özellikle 2008 ekonomik krizi sonrası Amerika Birleşik Devletleri (ABD) ve gelişmekte olan piyasalar, özellikle BRIC piyasaları, arasındaki entegrasyon birçok çalışmada incelenmiştir. Bu çalışmalardan bazıları ülkeler arasında dinamik bir etkileşimin varlığını ve kriz sonrası bu ülkelerin daha entegre hale geldiğini gösterirken (bkz. Aloui vd., 2011:131; Kenourgios vd., 2011:94; Berger ve Turtle, 2011:33), bazıları da özellikle krizin erken evrelerinde herhangi bir bulaşma etkisini doğrulamamakta ve izolasyon ve ayrılma belirtilerinin varlığını göstermiş̧tir. Ancak krizin ilerleyen saflarında, piyasaların tekrar entegre hale gelmesi, yatırımcıların risk iştahlarında değişiklik meydana geldiği şeklinde yorumlanmıştır (Dimitriou vd., 2013:47). Bu bulgu, yatırımcıların riskten kaçınma derecelerinin uluslararası piyasa entegrasyonu üzerindeki etkilerini konu alan literatürdeki az sayıda çalışmada irdelenmiş, riskten kaçınmanın hisse senedi piyasası korelasyonları üzerindeki olumlu etkisi ve hisse senedi piyasalarınının birlikte hareketini büyük oranda açıklayabileceği gösterilmiştir (bkz. Demirer vd., 2018:118; Xu, 2019:2). Öte yandan, Asya krizi ve 2008 ekonomik krizi karşılaştırıldığında, bu iki kriz dönemlerinde riskten kaçınmanın entegrasyon üzerinde heterojen etkiler sergilediği, Asya krizi esnasında Brezilya dışında diğer gelişmekte olan ülkeler için, riskten kaçınmanın entegrasyonu düşürdüğü saptanmıştır. Asya krizi döneminde küresel riskten kaçınma seviyesinin artmasıyla birlikte, yatırımcıların yatırımlarını az güvenilir bulduğu gelişmekte olan piyasalardan, daha güvenilir bulduğu gelişmiş piyasalara yeniden tahsisi nedeniyle entegrasyonun azaldığı savunulmuştur. Bu bulgu, riskten kaçınma gibi nakit akışı ile ilgili olmayan şokların hisse senedi piyasaları üzerindeki önemini vurgularken, bu tür şokların etkisinin gelişmekte olan piyasalarda oldukça heterojen ve krizin doğasına dayalı olduğunu göstermektedir (Demirer vd., 2018:121).

Riskten kaçınma etkisinin esas olarak kriz dönemlerinden kaynaklandığını gösteren bulgular, ortaya çıktığı 2019 senesinin Aralık ayından itibaren sadece sağlık sistemi üzerinde değil küresel ekonomi ve finans piyasaları üzerinde de olumsuz etkilere sahip olan ve tarihteki en güçlü bulaşıcı hastalıklardan biri olarak kabul edilen yeni tip koronavirüs (COVID-19) salgının etkilerini araştırma ihtiyacı doğurmuş̧ur. Baker vd. (2020), artan bilgi miktarı ve bu bilgilere erişim kolaylığı nedeniyle, COVID-19'un sonuçlarının şiddetinin, önceki pandemi ve krizlere nazaran daha net bir şekilde gözlemlendiğini vurgulamıştır. Bu bilgiler ışığında bu çalışma, yatırımcıların zamanla değişen riskten kaçınma düzeylerinin Amerika Birleşik Devletleri (ABD) ve BRIC (Brezilya, Hindistan, Rusya, Çin) hisse senedi piyasaları arasındaki entegrasyona COVID-19 ve 2008 krizi süresince olan etkisini 
incelemektedir. BRIC ülkelerinin hisse senedi piyasası korelasyonları üzerindeki nakit akışına bağlı olmayan şokların önemi araştırılarak, duygu temelli faktörler ile hisse senedi getiri dinamikleri arasında doğrudan bir bağlantı kurulması hedeflenmektedir.

Çalışmanın literatüre katkısı iki şekildedir. Öncelikle salgın veya pandemilerin hisse senedi piyasalarının entegrasyonu üzerindeki etkileri ile ilgili çok sayıda çalışma bulunmamaktadır (Chen vd., 2018:908). Bu çalışma, yeni tip koronavirüs salgını süresince riskten kaçınma düzeyindeki değişikliğin $\mathrm{ABD}$ ve BRIC piyasaları arasındaki entegrasyona etkilerini inceleyen ilk makale olarak bu boşluğu doldurmayı hedeflemektedir. Guiso vd. (2018), riskten kaçınma düzeyinin zaman içinde değişmesinin birincil nedeninin servet veya beklenen gelirdeki değişiklikler değil, korkudan kaynaklı duygu temelli değişiklikler olduğunu ileri sürmüştür. Bu bulgu ile ilintili olarak bu makalede, pandemi ve ekonomik kriz dönemi karşılaştırılarak, finansal şoklar nedeniyle meydana gelen değişikliklerden ziyade, korku temelli değişen bir faktörün piyasalar arası entegrasyonu nasıl etkilediği araştırılarak, ilgili literatüre davranışsal bir perspektif katılması hedeflenmiştir. Çalışmanın literatüre ikinci katkısı ise, riskten kaçınma düzeyindeki değişikliğin $\mathrm{ABD}$ ve BRIC ülkeleri arasındaki dinamik korelasyon üzerindeki asimetrik etkisini gösteren ilk çalışma olmasıdır. Riskten kaçınma düzeyindeki değişikliklerin asimetrik bir etki yaratıp yaratmadığının incelenmesi, davranışsal bağlamda yatırımcıların riskten kaçınma düzeylerindeki değişimlerin yönünün, farklı yatırım kararlarına neden olup olmadığının gözlemlenmesi imkânı sunmaktadır.

Çalışmanın sonraki bölümü literatürü özetlerken, üçüncü bölümde kullanılan veri ve yöntem anlatılmaktadır. Dördüncü bölümde ampirik bulgular sunulmuştur. Son bölüm ise çalışmanın sonuçlarından bahsetmektedir.

\section{LITERATÜR}

Son yıllarda, gelişmekte olan piyasalar, gelişmiş piyasalardaki yatırımcılara çeşitlendirme faydaları sundukları için önemli bir varlık sınıfı haline gelmiştir. Brezilya, Rusya, Hindistan ve Çin'in oluşturduğu BRIC ekonomileri, demografik potansiyelleri ve gelecek vaat eden ekonomik perspektifleri ile diğerlerinden ayrılan gelişmekte olan piyasa ekonomileridir. Bu nedenle, BRIC ülkeleri sadece yatırımcılardan değil politika yapıcılardan da büyük ilgi görmektedir. Bu ülkeler, dünya borsa kapitalizasyonunun $\% 41$ 'ini oluşturmakta, ve bunlardan Çin'in tek başına 2030'a kadar dünyanın en büyük hisse senedi piyasası olması beklenmektedir (Mensi vd., 2016:257). Öte yandan, gelişmekte olan piyasalar, finansal kurumlarının ve düzenleyici sistemlerinin zayıflığı ve olgunlaşmamışlığı nedeniyle, başta ABD olmak üzere gelişmiş piyasalardan gelen dış şoklara karşı çok hassas ve savunmasızdır. Bir ülkedeki ekonomik ve finansal sistem bozuklukları, doğrudan veya dolaylı olarak dünyadaki diğer ülkelere önemli ölçüde aktarılabilmektedir. Ayrıca, bu bozukluklar dünyanın önde gelen ekonomilerinden birinden kaynaklandığında bu etkinin büyüklügü daha da önemli hale gelmektedir (Forbes ve Chinn, 2004:705). Küresel ekonomik kriz, ABD’de ortaya çıkmasından çok kısa bir süre sonra tüm dünyayı etkilemiştir. Ekonomik krizin, ülke piyasalarına etkileri konusunda ise fikir birliği sağlanamamıştır. Bekiros (2013) çalışmasında, BRIC ülkelerinin 2008 ekonomik krizinden bu yana uluslararası olarak daha entegre hale geldiğini göstermiştir. Benzer şekilde Aloui vd. (2011) ABD ve BRIC piyasaları arasında zamanla değişen bağımlılığın varlığını ampirik olarak gözler önüne sermiştir. Kenourgious vd. (2011), sadece 2008 ekonomik krizi değil, 1995'ten itibaren gerçekleşen beş faklı ekonomik krizin ABD, İngiltere ve BRIC piyasaları arasındaki bulaşa etkilerini inceleyerek, 
krizin başladığı ülkeden diğer ülkelere doğru bir bulaş etkisi olduğunu ifade etmiştir. Berger ve Turtle (2011), bu krizin küresel yayılma ve bulaşma etkilerinin, BRIC ülkeleri ve ABD arasındaki dinamik bir etkileşimin varlığını gösterdiğini savunarak bu çalışmaları desteklemiştir. $\mathrm{Bu}$ bulgular, uluslararası yatırımcılar için özellikle BRIC hisse senedi piyasalarının, küresel yatırım, spekülasyon ve risk çeşitlendirme fırsatlarını arttırabileceğini ifade etmektedir. Öte yandan, Dimitriou vd. (2013)'nin de içinde bulunduğu az sayıda çalışma, özellikle 2008 ekonomik krizinin erken dönemlerinde, ABD ve BRIC piyasalarının birbirinden ayrıldığını ve bir bulaş etkisinin bulunmadığını, fakat krizin geç dönemleri için bir bulaş etkisinin varlığından söz edilebileceğini ileri sürmektedir. Dimitriou vd. (2013) bulaş etkisinde meydana gelen bu değişikliğin yatırımcıların risk iştahında meydana gelen değişimden kaynaklandığını belirterek, piyasalar arası entegrasyonun, duygu temelli değişimlerden de etkilenebileceğini ileri süren literatüre destek sağlamıştır.

Artan ampirik bulgular, krizlerin ülke sınırları boyunca yayılmasının "temellere dayalı" olabileceğini gösterirken, kriz aktarımı temellerdeki değişikliklerle ilgili olmadığında "saf bulaşma"nın da ortaya çıkabileceğini ifade etmektedir (Broner vd., 2006:204). Bu durumda bulaşma, yatırımcı davranışındaki değişikliklerden kaynaklanmaktadır (bkz.Masson, 1999; Allen ve Gale, 2001). Riskten kaçınma düzeyininin, piyasalar arasındaki entegrasyon açısından önem taşıdığını gösteren pek çok çalışma, "saf bulaşma" görüşünü destekler niteliktedir. Çalışmalar, küresel riskten kaçınmanın, ABD para politikasının yabancı ülkelere ihraç edildiği anahtar bir aktarım aracı olduğunu öne sürmektedir (Miranda-Agrippino ve Rey; 2015:3). Demirer vd. (2018) küresel riskten kaçınma düzeyi ve gelişmekte olan ülkelerin hisse senedi piyasası korelasyonları arasında doğrudan bir bağlantı bularak, nakit akışına bağlı olmayan faktörlerin bulaşma ve portföy riski modellerinde dikkate alınması gerektiğini ileri sürmektedir. Bu sonuç aynı zamanda Guiso vd. (2018)'nin ileri sürdüğü, servet veya beklenen gelirdeki değişikliklerden ziyade, yatırımcıların fayda fonksiyonundaki korku kaynaklı duygu temelli değişikliklerin riskten kaçınmadaki değişiminin birincil itici gücü olduğu bulgusunu desteklemektedir. Guiso vd. (2018), portföy verilerini kullanarak ve bir İtalyan bankasının müşterileriyle düzenli olarak gerçekleştirdiği anketlerden yararlanarak, yatırımcıların 2008 krizinden sonra riskten kaçınma eğiliminin artıp artmadığını test etmiş ve olumsuz bir şokla karşılaşan bireylerin hem finansal hem de finansal olmayan alanlarda risk alma isteklerini değiştiren bir duygudan (korkudan) etkilendiğine dair Loewenstein (2000) hipoteziyle tutarlı sonuçlar elde etmiştir. Duyguların riskten kaçınma oranını artırabileceğini gösteren Knutson vd. (2008)'a destek olarak, Guiso vd. (2018) olumsuz bir şokla ilişkili korkunun gerçekten de riskten kaçınma düzeyini değiştirdiğini ve ekonomik kriz sırasında riskten kaçınma artışının korku temelli olduğunu göstermiştir. Demirer vd. (2018) ise riskten kaçınmanın hisse senedi piyasası korelasyonları üzerindeki güçlü olumlu etkisini göstererek, duygu temelli faktörler ve hisse senedi getiri dinamikleri arasında ampirik olarak doğrudan bir bağlantı kurmuştur. Benzer şekilde Xu (2019) küresel riskten kaçınma endeksinin, sekiz adet gelişmiş ülke piyasasının beraber hareket etme davranışının yüzde 90'ını açıkladığını göstererek literatüre katkı sağlamıştır. Son olarak, Rey (2018), volatilite endeksi (VIX) ve riskten kaçınma ile birlikte hareket eden sermaye akışlarında, küresel bir finansal döngünün varlığından bahsetmiştir. Öte yandan bazı çalışmalarda, gelişmekte olan piyasaların küresel riskten kaçınma şoklarına tepki verme biçimlerinde mutlaka homojen olmadığı, bu piyasalardan bazıları için riskten kaçınma etkisinin esas olarak kriz dönemlerinden kaynaklandığı ve Asya ve küresel kriz dönemlerinin, riskten kaçınmanın korelasyonlarla ilişkisi üzerinde heterojen 
etkiler sergilediği ifade edilmiştir (bkz. Didier vd., 2012:2075; Demirer vd., 2018:121). Tsai (2014), korku endeksinin ABD ve diğer pazarlar arasındaki eşbütünleşme ile anlamlı olarak ilişkili olduğu sadece üç dönem olduğunu, bunların da 1997 öncesi dönem, dot-com balonunun olduğu 2000-2002 arası dönem, ve 2008 ekonomik krizinin patlak verdiği dönem olduğunu ifade etmiştir. Riskten kaçınmanın gelişmekte olan piyasalardaki korelasyonlara etkisindeki heterojenlik, küresel ekonomik krizin ardından gelişmekte olan ülkelerde gözlemlenen tepki ve toparlanma miktarlarındaki heterojenlikle örtüşmektedir (Didier vd., 2012:2075). Literatürde altı çizilen krizler ve ülkeler arasındaki heterojenliğin, COVID-19 pandemisi için de var olup olmadığı ile ilgili ise henüz yeterli sayıda çalışma yoktur.

Riskten kaçınma düzeyinin küresel bir salgın olan COVID-19 pandemi dönemindeki etkileri hala izaha muhtaç durumdadır. Azimli (2020), hisse senedi piyasalarının risk-getiri ilişkilerinin yapısı açısından COVID-19'a verdikleri tepkinin bulaş benzeri bir yol izlediğini ve pandeminin 2008 krizine benzer sonuçlar doğurduğunu ifade etmiştir. Benzer şekilde Choi (2020), COVID-19'un ABD borsasının tüm sektörleri üzerinde önemli bir etkisi olduğunu gösterirken, salgının çalışmanın yapıldığı pandeminin ilk zamanlarındaki endüstriyel ekonomi üzerindeki etkisinin 2008 krizinden daha büyük olduğunu belirtmiştir. COVID-19 ve 2008 ekonomik krizleri arasındaki farkları vurgulayan Harvey (2020), ortaya çıkan pandemi krizini "büyük sıkışma" olarak adlandırmıştır. Bu çalışma riskten kaçınma derecesindeki olumlu ve olumsuz değişimlerin, ABD ve BRIC ülkeleri arasındaki entegrasyona etkisinin COVID-19 pandemisi ve 2008 krizlerinde farklılık gösterip göstermediğini inceleyerek literatüre katkıda bulunmayı hedeflemektedir.

\section{VERI SETİ VE YÖNTEM}

\subsection{Veri}

Çalışmada tüm değişkenler için ortak olarak elde edilebilen en uzun zaman aralığı olan 1 Ocak 2006-28 Ekim 2020 tarihlerini kapsayan günlük zaman serileri kullanılmıştır. Alt örneklemler olarak ise, 2008 krizindeki etkiler için krizin erken aşamalarının da gözlemlenebileceği 3 Mart 2008- 31 Aralık 2009 tarihleri arası incelenirken (Dimitriou vd., 2013:48; Demirer vd., 2018:119), pandemi dönemindeki etkileri araştırılırken, ilk vakanın görüldüğü ve hastalığın tanımlandığı 31 Aralık 2019'dan 28 Ekim 2020’ye kadarki zaman aralığı kullanılmıştır (bkz. Corbet vd., 2021:55). Hindistan, Brezilya, Rusya, Çin ve ABD için sırasıyla NIFTY 50, BOVESPA, RTS, SSE ve S\&P 500 endeks verileri kullanılmıştır. Hisse senedi piyasası getirileri olarak, endekslerin kapanış fiyatlarının ilk logaritmik farkları kullanılmıştır. Veriler, investing.com internet sitesinden temin edilmiştir. Çalışmada ABD ve BRIC ülkelerinin incelenmesinin başlıca üç nedeni bulunmaktadır. Öncelikle, Goldman Sachs, BRIC ülkelerinin 2050 yılına kadar dünyanın baskın mamul mal ve hizmet tedarikçileri (Çin ve Hindistan) ve dünyanın baskın hammadde tedarikçileri (Brezilya ve Rusya) olacaklarını bildirmektedir. Ayrıca, yatırımcıların portföylerinde BRIC pazarlarının ağırlığının da keskin bir şekilde artacağı beklenmektedir (Kocaarslan vd., 2018:546). Son olarak, yapılan çalışmalar, emtia fiyatı değişikliğine karşı daha yüksek duyarlılığa sahip ülkelerin hem yükseliş hem düşüş piyasalarında ABD ile benzer şekilde hareket etme eğiliminde olduklarını bulmuştur (Aloui vd., 2011:140). 
Tablo 1. Tanımlayıcı İstatistikler

\begin{tabular}{|c|c|c|c|c|c|c|c|c|c|c|}
\hline & RABD & RBREZILYA & RHINDİSTAN & RRUSYA & RÇİN & RA & DCCBREZILYAABD & DCCHINDISTANABD & DCCRUSYAABD & DCCÇİNABD \\
\hline Ortalama & 0,0001 & 0,0003 & 0,0004 & 0 & 0,0003 & 2,8625 & 0,546 & 0,228 & 0,412 & 0,081 \\
\hline Medyan & 0,0003 & 0 & 0,0002 & 0,0003 & 0,0001 & 2,5418 & 0,305 & 0,113 & 0,228 & 0,051 \\
\hline Maksimum & 0,0453 & 0,1547 & 0,1633 & 0,202 & 0,0903 & 29,6474 & 13,195 & 5,79 & 6,972 & 0,978 \\
\hline Minimum & $-0,0554$ & $-0,1599$ & $-0,1523$ & $-0,2467$ & $-0,1276$ & 2,2696 & 0,008 & 0,003 & 0,007 & $-0,064$ \\
\hline Standard Sapma & 0,0056 & 0,0178 & 0,0145 & 0,0215 & 0,0161 & 1,437 & 0,993 & 0,48 & 0,691 & 0,1 \\
\hline Çarpıklık & $-0,6163$ & $-0,3505$ & $-0,5893$ & $-0,8936$ & $-0,674$ & 10,8033 & 6,653 & 6,563 & 5,413 & 3,913 \\
\hline Basıklık & 16,3478 & 13,0665 & 18,1666 & 18,5078 & 8,7973 & 159,6377 & 55,925 & 54,068 & 37,082 & 24,35 \\
\hline Jarque-Bera & 27701,24 & 15698,16 & 35676,47 & 37568,44 & 5461,45 & 3854508 & 458389,4 & 427913,9 & 196827,7 & 79585,28 \\
\hline Olasılık & 0 & 0 & 0 & 0 & 0 & 0 & 0 & 0 & 0 & 0 \\
\hline Gözlem & 3700 & 3700 & 3700 & 3700 & 3700 & 3700 & 3694 & 3694 & 3694 & 3694 \\
\hline
\end{tabular}


Tablo 1'de gösterilen değişkenlere ait tanımlayıcı istatistikler, normallik için uygulanan Jarque-Bera testi ile birlikte çarpıklık ve basıklık sonuçlarının, BRIC ve ABD pazarları için günlük getirilerin asimetrik olduğu ve Gauss dağılımından daha fazla kalın kuyruklu dağılıma ve yüksek zirveye sahip olduğunu göstermektedir. Bu sonuçlar GARCH etkileriyle tutarlıdır. Dahası, Engle'nin (1982) ARCH etkilerine dayanarak, ARCH etkilerinin olmadığı sıfır hipotezi de reddedilmiştir (Kocaarslan vd., 2018:553). Getiri endeksi korelasyon katsayıları Tablo 2'de sunulmuştur. ABD ile en yüksek korelasyona hammadde tedarikçisi olan Brezilya'nın, en düşük korelasyona ise mamul mal ve hizmet tedarikçisi olan Çin'in sahip olduğu gözlemlenmiştir. Bulgular, incelenen dönem için, diğer BRIC piyasaları ve ABD piyasası ile en az ilişkili piyasanın Çin olduğu yönündedir.

Tablo 2. Getiri Endeksleri Korelasyon Katsayıları

\begin{tabular}{lccccc}
\hline & RABD & RBREZILYA & RHINDISTAN & RRUSYA & RÇİN \\
\hline RABD & 1.0000 & 0.6623 & 0.2952 & 0.3704 & 0.0941 \\
RBREZILYA & 0.6623 & 1.0000 & 0.3194 & 0.4129 & 0.1593 \\
RHINDISTAN & 0.2952 & 0.3194 & 1.0000 & 0.4101 & 0.2458 \\
RRUSYA & 0.3704 & 0.4129 & 0.4101 & 1.0000 & 0.1902 \\
RÇIN & 0.0941 & 0.1593 & 0.2458 & 0.1902 & 1.0000 \\
\hline
\end{tabular}

Not: Tablo 2'de getiri endekslerinin korelasyon katsayıları sunulmuştur. RABD, RBREZILYA, RHİNDİSTAN, RRUSYA, ve RÇIN sırasıyla SP500, Bovespa, Nifty50, RTSI, ve SSE endeks getirilerini belirtmektedir.

Tablo 3. Birim Kök Testi Sonuçları

\begin{tabular}{|c|c|c|c|c|}
\hline & & \multicolumn{2}{|c|}{ DF-GLS } & \multirow{2}{*}{$\begin{array}{c}\text { PP } \\
\text { Statistics }\end{array}$} \\
\hline & & Statistics & Lag & \\
\hline RABD & \multirow{10}{*}{ Kesişim } & $-12,657 * * *$ & 10 & $-71,676^{* * *}$ \\
\hline RBREZILYA & & $-1,791 *$ & 20 & $-66,108 * * *$ \\
\hline RHINDISTAN & & $-60,786 * * *$ & 0 & $-60,815 * * *$ \\
\hline RRUSYA & & $-1,821^{*}$ & 27 & $-56,339 * * *$ \\
\hline RÇİN & & $-6,401^{* * *}$ & 15 & $-61,311^{* * *}$ \\
\hline RA & & $-4,991^{* * *}$ & 22 & $-28,011 * * *$ \\
\hline DCCBREZILYAABD & & $-5,642 * * *$ & 21 & $-6,904 * * *$ \\
\hline DCCHINDISTANABD & & $-6,211 * * *$ & 21 & $-6,731 * * *$ \\
\hline DCCRUSYAABD & & $-4,784 * * *$ & 23 & $-6,144 * * *$ \\
\hline DCCÇİNABD & & $-5,739 * * *$ & 2 & $-7,301 * * *$ \\
\hline RABD & \multirow{5}{*}{ Kesişim ve Trend } & $-33,237 * * *$ & 2 & $-71,705^{* * *}$ \\
\hline RBREZILILA & & $-4,121 * * *$ & 16 & $-66,099 * * *$ \\
\hline RHINDİSTAN & & $-60,566 * * *$ & 0 & $-60,809 * * *$ \\
\hline RRUSYA & & $-8,235^{* * *}$ & 13 & $-56,333^{* * *}$ \\
\hline RÇìN & & $-12,303 * * *$ & 11 & $-61,320 * * *$ \\
\hline
\end{tabular}


RA

DCCBREZILYAABD

DCCHINDISTANABD

DCCRUSYAABD

DCCÇINABD

$\begin{array}{lcc}-5,292^{* * *} & 22 & -28,184^{* * *} \\ -6,206^{* * *} & 21 & -6,945^{* * *} \\ -6,700^{* * *} & 21 & -6,757^{* * *} \\ -5,820^{* * *} & 25 & -6,179^{* * *} \\ -6,862^{* * *} & 2 & -7,301^{* * *}\end{array}$

Not: Tablo 3'de kullanılan değişkenlerin birim kök testi sonuçları sunulmuştur. RABD, RBREZİLYA, RHİNDİSTAN, RRUSYA, RÇIN, RA, DCCBREZILYAABD, DCCHINDISTANABD, DCCRUSYAABD, DCCÇINABD sırasıyla SP500, Bovespa, Nifty50, RTSI, ve SSE endeks getirileri, zamanla değişen riskten kaçınma düzeyini, Brezilya-ABD, HindistanABD, Rusya-ABD, ve Çin-ABD arasındaki dinamik şartlı korelasyonları belirtmektedir. DF-GLS ve PP, Dickey-Fuller-GLS ve Phillips-Perron birim kök testlerini ifade etmektedir. ${ }^{* * *},{ }^{* * *},{ }^{*}$ sirasıyla yüzde 1 , yüzde 5 , ve yüzde 10 seviyesinde anlamlılı̆̆ 1 göstermektedir.

Riskten kaçınma, servet, arka plan riski ve risk iştahını değiştiren duygulardaki değişiklikler nedeniyle dalgalanabilmektedir (Guiso vd., 2018:404). Bu ayrımı ele almak için Bekaert vd. (2019), hiperbolik mutlak riskten kaçınma (HARA) sınıfındaki bir fayda fonksiyonuna dayalı olarak zamanla değişen riskten kaçınma için bir formülasyon türetmiştir. $\mathrm{Bu}$ riskten kaçınma ölçüsü (RA), ekonomik belirsizlikteki zamanla meydana gelen değişimi (yani risk miktarını) risk tercihlerinde zamanla meydana gelen değişikliklerdeki (yani riskin fiyatından) ayırmaktadır. Bu veri sayesinde, ekonomik belirsizlikten bağımsız olarak, riskten kaçınma düzeyinin, BRIC ülkeleri ve ABD piyasası entegrasyonuna etkilerinin 2008 krizi ve COVID-19 pandemisi süresince değişiklik gösterip göstermediğini inceleme imkânı oluşmuştur.

Değişkenlerin durağanlık derecelerini bulmak amacıyla, literatürde sıkça kullanılan artırılmış Dickey Fuller- GLS (DF-GLS) (1979) ve Phillips-Perron (1988) birim kök testleri uygulanmıştır. Sıfır hipotezleri reddedilirse değişkenler durağan olarak kabul edilmektedir. $\mathrm{Bu}$ testlerin bulguları Tablo 3'de gösterilmiştir. Bu çalışmada kullanılan tüm birim kök testleri, ilgili değişkenlerin durağan olduğunu ifade etmektedir.

Ülkeler arası entegrasyon değişkeni olarak, VAR(5)-DCC-GARCH modellerinden elde edilen şartlı varyanslar kullanılmıştır. Bahsi geçen model ve diğer kullanılan ampirik yöntemler bir sonraki bölümde detaylı olarak anlatılmıştır.

\subsection{Yöntem}

Çalışmada ABD ve BRIC hisse senedi piyasaları arasındaki dinamik korelasyonları incelemek için VAR(5)-DCC-GARCH(1,1) metodolojisi kullanılmıştır. Eş zamanlı olmayan ticaret ve seri korelasyonları dikkate almak için, vektör otoregresif (VAR) bağlamı kullanılmaktadır (Forbes ve Rigobon, 2002:2236). Analizlerimizde Schwarz bilgi kriterine göre VAR (5) spesifikasyonu tercih edilmiştir. İlk adımda, piyasalar arasındaki doğrusal ilişki, denklem 1'de gösterildiği şekilde elde edilmiştir;

$$
Y_{t}=\vartheta_{0}+\sum_{i=1}^{n} \vartheta_{i} Y_{t-i}+\epsilon_{t}
$$

$Y_{t} A B D$ ve BRIC ülkeleri endeks getirilerini gösteren vektördür. 
Ardından denklem 2 kullanılarak, artık değerleri elde etmek için $\operatorname{GARCH}(1,1)$ modeli kullanılmıştır.

$$
h_{t}=\mu_{0}+\sum_{i=1}^{p} \mu_{i} \varepsilon_{t-1}^{2}+\sum_{j=1}^{q} \rho_{j} h_{t-j}
$$

Sabit parametreler $\mu_{0}, \mu_{i}$, ve $\rho_{j}$ ile gösterilmiştir.

Korelasyon parametrelerini elde etmek için korelasyon gelişimini veren DCC-GARCH modelini gösteren denklem 3'ten yararlanılmıştır.

$$
\begin{aligned}
& Q_{t}=(1-x-y) \bar{\theta}+x\left(\epsilon_{t-1} \epsilon_{t-1}^{I}\right)+y\left(Q_{t-1}\right) \\
& \theta_{t}=Q_{t}^{*-1} Q_{t} Q_{t}^{*-1}
\end{aligned}
$$

$\mathrm{x}$ ve $\mathrm{y}, \mathrm{x}+\mathrm{y}<1$ ve $\bar{\theta}=E\left[\epsilon_{T} \epsilon_{T}^{\prime}\right]$ ifadelerini sağlayan ölçekleyicilerdir. $Q_{t}^{*} \mathrm{i}$. diyagonel yerinde köşegen elemann karekökü olan köşegen bir matrisi ifade etmektedir (bkz. Engle, 2002; Kocaarslan vd., 2018: 556).

Ardından, riskten kaçınma düzeyinin $\mathrm{ABD}$ ve BRIC arasındaki entegrasyona etkilerini analiz etmek için gecikmesi dağıtılmış doğrusal olmayan otoregresif model (NARDL) kullanılmıştır. Öncelikle, değişkenlerin durağanlık özellikleri, artırılmış Dickey-Fuller, GLSve Phillips-Perron birim kök testleri kullanılarak incelenmiştir (bkz. Dickey ve Fuller, 1979; ve Phillips \& Perron, 1988). NARDL yaklaşımı, değişkenlerin ikinci dereceden entegre olmamasını gerektirmektedir (Shin vd., 2014; Peseran ve Shin, 1998). Değişkenlerin entegrasyon dereceleri belirlendikten sonra değişkenler arası uzun dönem eş bütünleşmeyi araştırmak için Sınır testi prosedürü uygulanmıştır. Doğrusal ARDL modellerinin hata düzeltme terimleri denklem 4-7 arasında gösterilmektedir.

\section{$\triangle D C C B R E Z \dot{I} L Y A A B D_{t}$}

$$
\begin{aligned}
& =\vartheta+\gamma_{1} \text { DCCBREZİLYABD } D_{t-1}+\gamma_{2} R A_{t-1}+\sum_{i=1}^{p-1} \mu_{1} \Delta \text { DCCBREZi } \\
& +\sum_{i=0}^{q-1} \mu_{2} \Delta R A_{t-i}+\varepsilon_{t}
\end{aligned}
$$

$\triangle D C C H \mathrm{I} N D \mathrm{I} S T A N A B D_{t}$

$$
\begin{aligned}
& =\vartheta+\gamma_{1} \text { DCCHїNDÍST ANABD } D_{t-1}+\gamma_{2} R A_{t-1} \\
& +\sum_{i=1}^{p-1} \mu_{1} \Delta D C C H \dot{\mathrm{I} N D I S T A N A B D} D_{t-i}+\sum_{i=0}^{q-1} \mu_{2} \Delta R A_{t-i}+\varepsilon_{t}
\end{aligned}
$$


$\triangle D C C R U S Y A A B D_{t}$

$$
\begin{aligned}
& =\vartheta+\gamma_{1} \text { DCCRUSYABD } D_{t-1}+\gamma_{2} R A_{t-1}+\sum_{i=1}^{p-1} \mu_{1} \Delta \text { DCCHRUSYAAB } \\
& +\sum_{i=0}^{q-1} \mu_{2} \Delta R A_{t-i}+\varepsilon_{t}
\end{aligned}
$$

$\triangle D C C \operatorname{ciN} A B D_{t}$

$$
\begin{aligned}
& =\vartheta+\gamma_{1} \operatorname{DCCÇINABD~}_{t-1}+\gamma_{2} R A_{t-1}+\sum_{i=1}^{p-1} \mu_{1} \Delta \operatorname{DCCCIN} A B D_{t-i} \\
& +\sum_{i=0}^{q-1} \mu_{2} \Delta R A_{t-i}+\varepsilon_{t}
\end{aligned}
$$

Denklemlerde değişkenlerin ilk farklılıkları $\Delta$ ile gösterilmektedir. Akaike Bilgi Kriteri (AIC), p ve q ile gösterilen gecikme uzunluklarını elde etmek için kullanılmıştır. $\gamma$ ve $\mu$ sırasıyla uzun ve kısa dönem katsayılarını temsil etmektedir.

Ayrıca, ilgili değişkenler arasındaki uzun ve kısa vadeli asimetrik bağlantılar NARDL modelleri ile analiz edilmiştir. NARDL modelleri, değişkenler arasındaki doğrusal olmayan ilişki nedeniyle ARDL modellerinde oluşabilecek yanıltıcı sonuçları önlemesi açısından tercih sebebidir. Dahası, NARDL içsellik ve yakınsama sorunlarından muaftır (Shin vd., 2014). Bu çalışmada kullanılan doğrusal olmayan uzun vadeli eş bütünleşme denklemi şu şekildedir;

$$
y_{t}=\lambda^{+} x_{t}^{+}+\lambda^{-} x_{t}^{-}+u_{t}
$$

Denklemde $x_{t}$ dinamik şartlı korelasyonları ve $y_{t}$ zamanla değişen riskten kaçınma düzeylerini belirtmekte ve $\lambda^{+}$ve $\lambda^{-}$uzun vadeli parametreleri ifade etmektedir. $\mathrm{x}_{\mathrm{t}}{ }^{+}$ve $\mathrm{x}_{\mathrm{t}}{ }^{-}$ise denklem 9 ve 10 'daki şekilde ifade edilmektedir.

$$
\begin{aligned}
& x_{t}^{+}=\sum_{i=1}^{t} \Delta x_{i}^{+}=\sum_{i=1}^{t} \max \left(\Delta x_{i}, 0\right) \\
& x_{t}^{-}=\sum_{i=1}^{t} \Delta x_{i}^{-}=\sum_{i=1}^{t} \max \left(\Delta x_{i}, 0\right)
\end{aligned}
$$


Çalışmada kullanılan NARDL modellerinin hata düzeltme modelleri ise denklem 11 ile 14 arasında gösterilmiştir;

$\triangle D C C B R E Z \dot{I} L Y A A B D_{t}$

$$
\begin{aligned}
& =\vartheta+\tau \text { DCCBREZi } L Y A A B D_{t-1}+\beta_{1}^{+} R A_{t-1}^{+}+\beta_{1}^{-} R A_{t-1}^{-} \\
& +\sum_{i=1}^{P-1} \rho \Delta D C C B R E Z \dot{\mathrm{I}} L Y A A B D_{t-i}+\sum_{i=0}^{q-1} \vartheta_{1}^{+} \Delta R A_{t-i}^{+}+\sum_{i=0} \vartheta_{1}^{-} \Delta R A_{t-}^{-}
\end{aligned}
$$

$\triangle D C C H$ İNDIST $A N A B D_{t}$

$$
\begin{aligned}
& =\vartheta+\tau \text { DCCHİNDisT ANABD } D_{t-1}+\beta_{1}^{+} R A_{t-1}^{+}+\beta_{1}^{-} R A_{t-1}^{-} \\
& +\sum_{i=1}^{P-1} \rho \Delta \text { DCCHі́NDİSTANBD } D_{t-i}+\sum_{i=0}^{q-1} \vartheta_{1}^{+} \Delta R A_{t-i}^{+}+\sum_{i=0} \vartheta_{1}^{-} \Delta R A_{t-}^{-}
\end{aligned}
$$

$\triangle D C C R U S Y A A B D_{t}$

$$
\begin{aligned}
& =\vartheta+\tau \text { DCCRUSYAABD } D_{t-1}+\beta_{1}^{+} R A_{t-1}^{+}+\beta_{1}^{-} R A_{t-1}^{-} \\
& +\sum_{i=1}^{q-1} \rho \Delta \text { DCCRUSYAABD } D_{t-i}+\sum_{i=0}^{q-1} \vartheta_{1}^{+} \Delta R A_{t-i}^{+}+\sum_{i=0}^{\eta_{1}^{-1}} \vartheta_{1}^{-} \Delta R A_{t-i}^{-}+
\end{aligned}
$$

$\triangle D C C$ ÇIN $A B D_{t}$

$$
\begin{aligned}
& =\vartheta+\tau D C C \text { ÇN } A B D_{t-1}+\beta_{1}^{+} R A_{t-1}^{+}+\beta_{1}^{-} R A_{t-1}^{-}+\sum_{i=1}^{P-1} \rho \Delta D C C \text { Çi } \\
& +\sum_{i=0}^{q-1} \vartheta_{1}^{+} \Delta R A_{t-i}^{+}+\sum_{i=0}^{q-1} \vartheta_{1}^{-} \Delta R A_{t-i}^{-}+\varepsilon_{t}
\end{aligned}
$$

Denklemlerde uzun vadeli katsayılar $\tau$ ve $\beta$ ile gösterilirken ve kısa vadeli katsayılar $\rho$ ve $\vartheta$ ile belirtilmiştir.

Uzun ve kısa dönem asimetrilerin varlığını incelemek amacıyla Wald testi uygulanmıştır (Shin vd., 2014). $\lambda^{+}=-\beta_{n}{ }^{+} / \tau$ and $\lambda^{-}=-\beta_{n}{ }^{-} / \tau$ denklemleri kullanılarak, $\lambda+=$ $\lambda$ - olan uzun dönem simetri test edilmiştir. Kısa dönem simetriyi incelemek için ise $\sum_{i=0}^{q-1} \vartheta_{k}^{+}=\sum_{i=0}^{q-1} \vartheta_{k}^{-}$sıfir hipotezi test edilmiştir.

\section{BULGULAR}

Çalışmada ilk olarak dinamik şartlı korelasyonlar VAR(5)-DCC-GARCH(1,1) yöntemiyle elde edilmiştir. Denklem 1'de gösterilen ortalama denkleminin bulguları Tablo 4'te verilmiştir. ABD'nin gecikmeli getirilerinin bütün BRIC ülkeleri endeks getirilerini istatistiksel olarak anlamlı bir şekilde öngördüğü görülmektedir. Öte yandan ABD’nin endeks getirileri sadece kendi, Hindistan ve Çin endekslerinin gecikmeli getirilerinden etkilenmektedir. Bu bulgu, BRIC ülkeleri ve ABD arasındaki dinamik bir etkileşimin varlığını 
gösteren diğer çalışmaları destekler niteliktedir (Kocaarslan vd., 2018:545; Berger ve Turtle, 2011:33; Kenourgios vd., 2011:105).

Tablo 5'te tek değişkenli $\operatorname{GARCH}(1,1)$ modellerinden elde edilen varyans denkleminin bulguları sunulmuştur. $\chi$ ve $\beta$ h sırasıyla ARCH ve GARCH parametrelerini temsil etmektedir. ARCH-GARCH parametrelerinin tamamı istatistiksel olarak anlamlıdır ve bu da şartlı değişken varyansın varlığını göstermektedir. Ayrıca, kısa vadeli ARCH parametrelerinin GARCH parametrelerinden daha küçük olması uzun vadeli oynaklı̆̆ın önemli etkisini göstermektedir (Uğurlu-Yıldırım, 2020:2769).

Tablo 4. Ortalama Denklemi Sonuçları

Bağımsız Değişken $\quad$ Bağımlı Değiş̧ken

\begin{tabular}{|c|c|c|c|c|c|}
\hline & RABD & RBREZİLYA & RHINDİSTAN & RRUSYA & RÇİN \\
\hline Sabit & $0,043 * * *$ & $0,112^{* * *}$ & $0,076^{* * *}$ & $0,081^{* * *}$ & 0,019 \\
\hline $\mathrm{RABD}(-1)$ & $-0,085 * * *$ & $0,139 * *$ & $0,600 * * *$ & $0,583^{* * *}$ & $0,425^{* * *}$ \\
\hline $\mathrm{RABD}(-2)$ & $-0,013$ & 0,004 & $0,173 * * *$ & $0,192 * *$ & 0,036 \\
\hline $\mathrm{RABD}(-3)$ & $-0,016$ & 0,017 & $0,086^{*}$ & $-0,017$ & 0,088 \\
\hline $\mathrm{RABD}(-4)$ & $-0,001$ & $-0,146 * *$ & 0,077 & $-0,012$ & 0,099* \\
\hline RABD(-5) & $-0,034 *$ & $-0,071$ & $-0,005$ & 0,114 & 0,069 \\
\hline RBREZILYA(-1) & $-0,003$ & $-0,104 * * *$ & $0,061^{* * *}$ & $0,155^{* * *}$ & $0,036 * *$ \\
\hline RBREZİLYA(-2) & $-0,003$ & $-0,023$ & $0,023^{*}$ & $0,063 * * *$ & 0,02 \\
\hline RBREZILYA(-3) & $-0,005$ & $-0,015$ & $0,023^{*}$ & $0,063 * * *$ & 0,005 \\
\hline RBREZİLYA(-4) & $-0,007$ & 0,005 & 0,013 & $0,061 * * *$ & 0,018 \\
\hline RBREZILYA(-5) & $-0,002$ & $-0,021$ & $-0,004$ & 0,02 & $-0,006$ \\
\hline RHINDİSTAN(-1) & $-0,007$ & 0,022 & $-0,037 * *$ & $-0,026$ & $-0,012$ \\
\hline RHINDİSTAN(-2) & $-0,016^{* * *}$ & $0,049 * *$ & $-0,022$ & 0,01 & 0,027 \\
\hline RHINDİSTAN(-3) & $-0,012 * *$ & 0,003 & $-0,038 * *$ & $-0,043^{*}$ & $-0,023$ \\
\hline RHİNDİSTAN(-4) & 0,001 & 0,001 & $-0,013$ & 0,025 & $-0,013$ \\
\hline RHİNDİSTAN(-5) & $-0,006$ & $-0,015$ & $-0,003$ & $-0,011$ & $-0,011$ \\
\hline RRUSYA(-1) & 0,003 & 0,016 & $-0,021^{*}$ & $-0,061^{* * *}$ & 0,008 \\
\hline RRUSYA(-2) & $-0,001$ & $-0,005$ & 0,001 & $-0,044^{* *}$ & $-0,01$ \\
\hline RRUSYA(-3) & 0,005 & $-0,015$ & $-0,005$ & 0,006 & $-0,014$ \\
\hline RRUSYA(-4) & $-0,003$ & 0,013 & $-0,01$ & $-0,054^{* * *}$ & 0,005 \\
\hline RRUSYA(-5) & 0,002 & $-0,014$ & $-0,006$ & $-0,011$ & 0,006 \\
\hline RÇİN(-1) & 0,001 & 0,01 & $-0,056^{* * *}$ & $-0,058^{* * *}$ & $-0,036 * *$ \\
\hline RÇİN(-2) & $-0,001$ & $-0,004$ & $-0,009$ & 0,007 & 0,005 \\
\hline RÇİN(-3) & $-0,003$ & $-0,02$ & 0,002 & $-0,029$ & 0,017 \\
\hline RÇİN(-4) & $-0,002$ & 0,017 & $-0,01$ & 0,02 & 0,01 \\
\hline RÇİN(-5) & $-0,008 * *$ & $-0,014$ & $-0,011$ & $-0,011$ & $-0,023$ \\
\hline
\end{tabular}

Not: Ortalama denkleminin sonuçları Tablo 4'te sunulmuştur. RABD, RBREZILLYA, RHİNDİSTAN, RRUSYA, ve RÇİN, sırasıyla SP500, Bovespa, Nifty, RTSI, ve SSE endeks getirilerini belirtmektedir. ***,**,* sirasıyla yüzde 1 , yüzde 5 , ve yüzde 10 seviyesinde anlamlılığı göstermektedir. 
Tablo 5. Varyans Denklemi Sonuçları

\begin{tabular}{lcccc}
\hline \multicolumn{1}{c}{ Piyasa Getirileri } & Model & $\beta_{0}$ & $\chi$ & $\beta \mathrm{h}$ \\
\hline RABD & & & & $0,846^{* * *}$ \\
RBREZILYA & GARCH(1,1) & $0,006^{* * *}$ & $0,125^{* * *}$ & $0,900^{* * *}$ \\
RHINDISTAN & GARCH(1,1) & $0,080^{* * *}$ & $0,065^{* * *}$ & $0,901^{* * *}$ \\
RRUSYA & GARCH(1,1) & $0,017^{* * *}$ & $0,094^{* * *}$ & $0,904^{* * *}$ \\
RÇIN & GARCH(1,1) & $0,071^{* * *}$ & $0,075^{* * *}$ & $0,940^{* * *}$ \\
\hline
\end{tabular}

Not: GARCH(1,1) modelleri için varyans denklemi sonuçları Tablo 5'te sunulmuştur. RABD, RBREZİLYA, RHINDİSTAN, RRUSYA, ve RÇiN, sırasıyla SP500, Bovespa, Nifty, RTSI, ve SSE endeks getirilerini belirtmektedir. ***,**,* sirasıyla yüzde 1 , yüzde 5 , ve yüzde 10 seviyesinde anlamlılı̆g göstermektedir. ARCH ve GARCH parametreleri sirasıyla $\chi$ ve $\beta$ h ile gösterilmiştir.

Çalışmanın sonraki adımında, tek değişkenli GARCH modellerinden standartlaştırılmış artık değerler elde edilmiş ve DCC-GARCH yöntemi kullanılarak piyasalar arasındaki dinamik şartlı korelasyonlar türetilmiştir. Şekil 1 piyasalar arasındaki dinamik şartlı korelasyonları göstermektedir. ABD ile Çin arasındaki düşük korelasyon, bu iki pazarı kullanarak portföy çeşitliliği sağlanabileceğini ima etmektedir. Bu iki pazar arasındaki düşük korelasyonların 2008 krizi ve COVID-19 pandemisi süresince sürekliliği, diğer BRIC ülkelerinin aksine, kriz dönemlerinde dahi bu iki pazar arasında çeşitlenme fırsatının sürdügünü ifade etmektedir. Bu durum, Longin ve Solnik (2001)'de belirtilen boğa piyasalarının entegrasyonlarının, sik meydana gelmeyen andak meydana geldiklerinde sonuçları çok büyük olan düşük frekansl1-yüksek şiddetli olaylarından önemli ölçüde etkilenmediği iddiasıyla uyum içerisindedir.

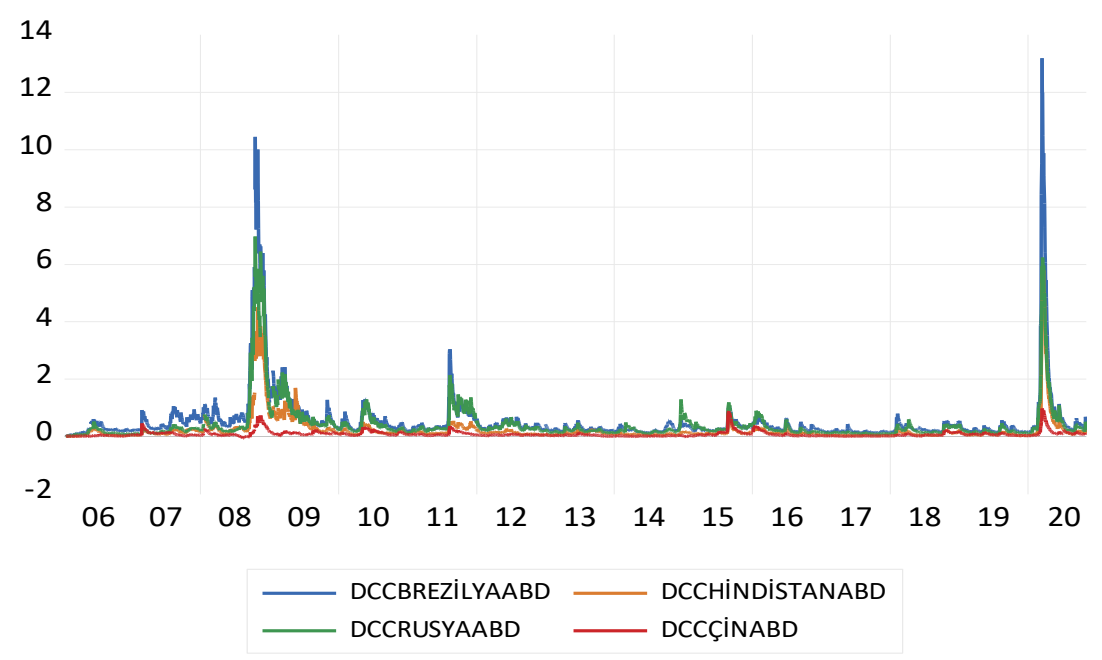

Grafik 1. ABD ve BRIC Piyasaları Arası Dinamik Şartlı Korelasyonları

NARDL testini uygulamadan önce yukarıdaki aşamada elde edilen dinamik şartlı korelasyon serilerinin durağanlık dereceleri, DF-GLS (1979) ve Phillips-Perron (1988) birim kök testleri yardımıyla incelenmiştir. Tablo 3'te sunulan sonuçlar, ABD ve BRIC ülkeleri arasındaki dinamik şartlı korelasyon serilerinin durağan olduğunu göstermektedir. $\mathrm{Bu}$ 
nedenle, değişkenlerin ikiden az derecede entegrasyonunu gerektiren NARDL modelleri tereddüt etmeden yürütülebileceği sonucuna ulaş1lmıştır (bkz. Shin vd., 2014; Peseran ve Shin, 1998).

Serilerin durağanlığı incelendikten sonra, riskten kaçınma düzeyindeki değişiklikler ve ülkeler arasındaki dinamik korelasyonlar arasındaki uzun vadeli eş bütünleşmenin varlığg sınır testi tekniği uygulanarak incelenmiştir. Bulgular Tablo 6'da sunulmuştur. ABD ve BRIC ülkelerinin dinamik şartlı korelasyonlarının bağımlı değişken olduğu dört model için de eş bütünleşme bağlantısının olmadığı boş hipotezini reddedilmektedir. Bu sonuçlar 1şığında ilgili değişkenler arasında en az yüzde bir düzeyinde uzun vadeli bir eş bütünleşmenin varlığ saptanmıştır.

Tablo 6. Sınır Testi Sonuçları

\begin{tabular}{|c|c|c|c|}
\hline \multirow[t]{2}{*}{ Eş bütünleşme hipotezi } & \multicolumn{3}{|c|}{ F İstatistiği } \\
\hline & Tüm örneklem dönemi & 2008 krizi & COVID-19 \\
\hline $\mathrm{F}\left(\mathrm{DCCBEZIL} \mathrm{IAABD}_{\mathrm{t}} / \mathrm{RA}_{\mathrm{t}}{ }^{+}, \mathrm{RA}_{\mathrm{t}}{ }^{-}\right)$ & $109,540 * * *$ & $14,923 * * *$ & $34,461 * * *$ \\
\hline $\mathrm{F}\left(\mathrm{DCCHINDİSTANABD} \mathrm{t}_{\mathrm{t}} / \mathrm{RA}_{\mathrm{t}}{ }^{+}, \mathrm{RA}_{\mathrm{t}}{ }^{-}\right)$ & $151,802^{* * *}$ & $41,093 * * *$ & $58,635 * * *$ \\
\hline $\mathrm{F}\left(\mathrm{DCCRUSYAABD} / \mathrm{RA}_{\mathrm{t}}{ }^{+}, \mathrm{RA}_{\mathrm{t}}{ }^{-}\right)$ & $79,096 * * *$ & $7,749 * * *$ & $34,125^{* * *}$ \\
\hline $\mathrm{F}\left(\mathrm{DCCÇİNABD}_{\mathrm{t}} / \mathrm{RA}_{\mathrm{t}}{ }^{+}, \mathrm{RA}_{\mathrm{t}}{ }^{-}\right)$ & $39,400 * * *$ & $7,316^{* * *}$ & $17,221 * * *$ \\
\hline
\end{tabular}

Not: Sınır testi sonuçları Tablo 6'da sunulmuştur. DCCBREZİLYAABD, DCCHİNDİSTANABD, DCCRUSYAABD, DCCÇİNABD, ve RA sırasıyla Brezilya-ABD, Hindistan-ABD, Rusya-ABD, ve Çin-ABD arasındaki dinamik şartlı korelasyonları, ve zamanla değişen riskten kaçınma düzeyini belirtmektedir. ${ }^{* * *}, * * *{ }^{*}$ sırasıyla yüzde 1 , yüzde 5 , ve yüzde 10 seviyesinde anlamlılığı göstermektedir. + ve - sırasıyla ilgili değişkenlerdeki pozitif ve negatif değişiklikleri gösterir.

Uzun ve kısa vadeli simetriyi inceleyen Wald testlerinin bulguları Tablo 7'de verilmiştir. Wald testi sonuçlarına göre, uzun vadede ilgili değişkenlerdeki pozitif ve negatif değişimlerin bağımlı değişkenler üzerinde genel olarak simetrik etkisi olduğu gözlemlenirken, riskten kaçınma düzeyindeki olumlu ve olumsuz değişikliklerin bütün dinamik şartlı korelasyon serileri üzerinde kısa vadede asimetrik etkileri olduğu saptanmıştır. Bu bulgular, NARDL yaklaşımının kullanılmasının modelimiz açısından uygun olduğunu kanıtlamaktadır.

Riskten kaçınma düzeyindeki olumlu ve olumsuz değişimlerin, ABD ve Brezilya arasındaki dinamik şartlı korelasyonuna etkileri tüm örneklem dönemi, 2008 krizi ve COVID19 pandemi süreci için Tablo 8'de gösterilmiştir. Buna göre, sadece 2008 krizi süresince riskten kaçınma düzeyindeki pozitif ve negatif değişimlerin $A B D$ ve Brezilya arasındaki korelasyona uzun dönemli anlamlı bir etkisinin olduğu ve bu etkinin simetrik ve negatif olduğu bulunmuştur. 2008 krizinde riskten kaçınma düzeyinde meydana gelen her türlü değişiklik, iki ülke arasındaki dinamik korelasyonu azaltmıştır. Bunun nedeni, ekonomik kriz döneminde yatırımcıların eş zamanlı olarak ABD ve Brezilya borsalarına yatırım yapmasını riskli bulmaları ve eş zamanlı olarak iki borsaya yatırım yapmaktan kaçınmaları olduğu şeklinde yorumlanabilir (Dakhlaoui ve Aloui, 2016:154). 
Tablo 7. WALD Testi Sonuçları

\begin{tabular}{|c|c|c|c|}
\hline \multicolumn{4}{|c|}{ Panel A, Uzun dönem asimetri } \\
\hline & Tüm örneklem dönemi & 2008 krizi & COVID-19 \\
\hline Bağımlı Değişken & \multicolumn{3}{|c|}{ Wud(RA) } \\
\hline$\Delta$ DCCBEZILYAABD & $7,0507 * * *$ & 1,0663 & 1,4917 \\
\hline$\triangle$ DCCHINDİSTANABD & 0,8685 & 0,7245 & $4,8604 * *$ \\
\hline$\triangle$ DCCRUSYAABD & 0,4319 & 0,0955 & $6,6623 * * *$ \\
\hline$\triangle$ DCCÇİNABD & 0,0397 & $2,8615 *$ & 0,054 \\
\hline \multicolumn{4}{|l|}{ Panel B, Kısa dönem asimetri } \\
\hline Bağımlı Değişken & \multicolumn{3}{|c|}{$\mathrm{W}_{\mathrm{KD}}(\mathrm{RA})$} \\
\hline$\triangle$ DCCBEZILYAAABD & $45,6834^{* * *}$ & $14,2893^{* * *}$ & $86,8103^{* * *}$ \\
\hline$\triangle$ DCCHINDİSTANABD & $45,0245^{* * *}$ & $29,1012 * * *$ & $42,2959 * * *$ \\
\hline$\triangle$ DCCRUSYAABD & $51,0971^{* * *}$ & $12,1326^{* * *}$ & $21,4514 * * *$ \\
\hline$\triangle$ DCCÇİNABD & $13,0650 * * *$ & $5,2091^{* * *}$ & $38,3131^{* * *}$ \\
\hline
\end{tabular}

Not: Uzun ve kısa vadeli asimetri bulguları için Wald testi sonuçları Tablo 7'de gösterilmiştir. DCCBREZILLYAABD, DCCHINDISTANABD, DCCRUSYAABD, ve DCCÇINABD sırasıly Brezilya-ABD, Hindistan-ABD, Rusya-ABD, ve Çin-ABD arasındaki dinamik şartlı korelasyonları WUD ve WKD uzun vadeli ve kısa vadeli Wald test değerlerini göstermektedir. ${ }^{* * *}, * * *$ sırasıly yüzde 1 , yüzde 5 , ve yüzde 10 seviyesinde anlamlılığ 1 göstermektedir.

Öte yandan riskten kaçınma düzeyinin ABD ve Brezilya arasındaki dinamik şartlı korelasyona kısa dönem etkileri ilgi çekicidir. Öncelikle, Tablo 7'de da belirtildiği üzere hem tüm örneklemler için riskten kaçınma düzeyinde meydana gelen pozitif ve negatif değişimlerin etkisinin asimetrik olduğu gözlemlenmiştir. Riskten kaçınma düzeyindeki pozitif değişiklikler genel olarak iki ülke endeksi arasındaki entegrasyonu arttırırken, negatif değişiklikler bu korelasyonu azaltmaktadır. Bireylerin daha fazla riskten kaçındıkları dönemlerde yatırımcıların iki piyasaya da yatırım yapıp portföylerini çeşitlendirmek istedikleri söylenebilir. 2008 krizi ve COVID-19 pandemisi karşılaştırıldığında, riskten kaçınma düzeyinin iki ülke arasındaki entegrasyona etkisinin COVID-19 süresince daha fazla ve istatistiksel olarak da daha anlamlı olduğu gözlemlenmektedir. Bunun yanı sira, düzeltilmiş $\mathrm{R}^{2}$ 'lere bakıldığında riskten kaçınma düzeyindeki değişiklikler $\mathrm{ABD}$ ve Brezilya arasındaki korelasyonun COVID-19 döneminde \%86,82'sini açıklarken, 2008 krizinde sadece \%42,85'ini açıkladığ1 görülmüştür. Bulgular, COVID-19 pandemisine bağlı ekonomik belirsizlik ile ABD'deki endüstriyel sektör arasındaki ilişkiyi 2008 krizinin etkisi ile kıyaslayan ve bu bağımlılığın 2008 krizinin yarattığından daha yüksek olduğunu ileri süren Choi (2020)'yi destekler niteliktedir. 
Tablo 8. NARDL Test Sonuçları (Bağımlı Değişken: $\triangle$ DCCBREZILYAABD)

\begin{tabular}{|c|c|c|c|c|c|c|}
\hline \multicolumn{7}{|l|}{ Panel A: Tahmini Katsayılar } \\
\hline \multirow[b]{2}{*}{ Bağımsız Değişkem } & \multicolumn{2}{|c|}{ Tüm örneklem dönemi } & \multicolumn{2}{|c|}{2008 krizi } & \multicolumn{2}{|c|}{ COVID-19 } \\
\hline & Katsayı & t-ist. & Katsay 1 & t-ist. & Katsayı & t-ist. \\
\hline $\mathrm{C}$ & $0,044 * * *$ & 6,26 & $0,116 * * *$ & 4,0508 & 0,2892 & 1,3999 \\
\hline DCCBEZİLYAABD $_{\mathrm{t}-1}$ & $-0,082 * * *$ & $-4,7022$ & $-0,074 * * *$ & $-2,6402$ & $-0,117 * * *$ & $-5,374$ \\
\hline $\mathrm{RA}_{\mathrm{t}-1}{ }^{+}$ & $-0,02$ & $-1,0007$ & $-0,050 * *$ & $-2,5449$ & 0,0685 & 0,9265 \\
\hline $\mathrm{RA}_{\mathrm{t}-1^{-}}$ & $-0,02$ & $-0,9962$ & $-0,050 * *$ & $-2,5304$ & 0,0695 & 0,9305 \\
\hline DDCCBEZİLYAABD $_{\mathrm{t}-1}$ & $-0,036$ & $-0,5259$ & $-0,0523$ & $-0,7161$ & & \\
\hline DDCCBEZİLYAABD $_{\mathrm{t}-2}$ & $-0,015$ & $-0,2591$ & $-0,117 *$ & $-1,6981$ & & \\
\hline DDCCBEZİLYAABDt-3 & 0,062 & 1,2088 & 0,0553 & 0,6943 & & \\
\hline DDCCBEZİLYAABDt-4 & & & $-0,1106$ & $-1,3066$ & & \\
\hline $\mathrm{DRA}_{\mathrm{t}}^{+}$ & $0,025^{*}$ & 1,9247 & 0,0331 & 1,4694 & 0,0296 & 1,1257 \\
\hline DRA $_{t-1}{ }^{+}$ & $0,188 * * *$ & 4,4346 & $0,186^{* * *}$ & 4,3028 & $0,189 * * *$ & 5,889 \\
\hline DRA $_{t-2}{ }^{+}$ & $-0,039$ & $-1,402$ & & & $-0,161^{* *}$ & $-2,4764$ \\
\hline DRA $_{t-3}{ }^{+}$ & 0,005 & 0,1437 & & & $0,108 *$ & 1,8405 \\
\hline DRA $_{t-4}{ }^{+}$ & $-0,054 * * *$ & $-3,5243$ & & & $-0,199 * * *$ & $-3,8164$ \\
\hline $\mathrm{DRA}_{t}^{-}$ & $-0,038$ & $-0,6128$ & $-0,0151$ & $-0,3488$ & $-0,0057$ & $-0,077$ \\
\hline $\mathrm{DRA}_{\mathrm{t}-1^{-}}$ & $-0,146 * * *$ & $-5,3062$ & $-0,154 * * *$ & $-5,9377$ & $-0,205^{* * *}$ & $-2,9388$ \\
\hline $\mathrm{DRA}_{\mathrm{t}-2^{-}}$ & $-0,022$ & $-0,7592$ & 0,0005 & 0,0216 & $0,140 * *$ & 1,8816 \\
\hline DRA $_{t-3}{ }^{-}$ & $-0,014$ & $-0,5955$ & $-0,0001$ & $-0,0053$ & $-0,228 * * *$ & $-2,6255$ \\
\hline $\mathrm{DRA}_{\mathrm{t}-4^{-}}$ & $0,035^{* *}$ & 2,4724 & $0,044 * *$ & 2,5506 & 0,0516 & 1,258 \\
\hline Düzeltilmiş $\mathrm{R}^{2}$ & \multicolumn{2}{|c|}{0,527} & \multicolumn{2}{|c|}{0,4285} & \multicolumn{2}{|c|}{0,8682} \\
\hline \multicolumn{7}{|c|}{ Panel B: Asimetrik parametreler için uzun dönem katsayılar } \\
\hline $\mathrm{RA}+$ & \multicolumn{2}{|c|}{$-0,24$} & \multicolumn{2}{|c|}{$-0,68 * *$} & \multicolumn{2}{|c|}{0,59} \\
\hline $\mathrm{RA}^{-}$ & \multicolumn{2}{|c|}{$-0,24$} & \multicolumn{2}{|c|}{$-0,68 * *$} & \multicolumn{2}{|c|}{0,59} \\
\hline
\end{tabular}

Not: $\triangle$ DCCBREZILIYAABD'nin bağımlı değişken olduğu NARDL test sonuçları Tablo 8'de verilmiştir. Panel A, NARDL modelinin hata düzeltme gösterimi sonuçlarını göstermektedir. Newey-West (1987) otokorelasyon ve heteroskedastisitesi sağlam t-istatistikleri rapor edilmiştir. . + ve - sırasıyla ilgili değişkenlerdeki pozitif ve negatif değişiklikleri göstermektedir. Panel B'de, ilgili değişkenlerin pozitif ve negatif değişimi ile ilişkili tahmini uzun-dönem katsayılar gösterilmiştir. ***,**,* sırasıyla yüzde 1 , yüzde 5 , ve yüzde 10 seviyesinde anlamlılı̆̆ göstermektedir.

Riskten kaçınma düzeyinin, ABD ve Hindistan borsa endeksleri arasındaki dinamik şartlı korelasyonuna etkileri Tablo 9'da sunulmuştur. Bu bulgulara göre, tüm örneklem dönemi için riskten kaçınma derecesindeki pozitif ve negatif değişikliklerin iki ülke arasındaki dinamik şartlı korelasyona uzun dönemde anlamlı bir etkisi bulunmazken, 2008 krizi döneminde ve COVID-19 süresince anlamlı etkileri olduğu gözlemlenmiştir. 2008 krizi döneminde riskten kaçınma düzeyindeki her türlü değişiklik iki ülke arasındaki korelasyonu azaltırken, pandemi süresince riskten kaçınma düzeyindeki değişikliklerin uzun dönemli korelasyonu arttırdığı bulunmuştur. $\mathrm{Bu}$ sonuçlar, 2008 krizi esnasında değişen riskten kaçınma düzeyinin yatırımcıların portföy riskini azaltmasına olanak sağlarken, COVID-19 esnasında riskten kaçınma düzeyindeki değişiklikler, yatırımcıların bu iki ülke piyasalarını kullanarak portföy çeşitlendirme imkanların azalttığını göstermektedir. 
Tablo 9. NARDL Test Sonuçları (Bağımlı Değişken: $\triangle$ DCCHİNDİSTANABD)

\begin{tabular}{|c|c|c|c|c|c|c|}
\hline \multicolumn{7}{|l|}{ Panel A: Tahmini Katsayllar } \\
\hline \multirow[b]{2}{*}{ Bağımsız Değişkem } & \multicolumn{2}{|c|}{ Tüm örneklem dönemi } & \multicolumn{2}{|c|}{2008 krizi } & \multicolumn{2}{|c|}{ COVID-19 } \\
\hline & Katsay 1 & t-ist. & Katsay 1 & t-ist. & Katsay 1 & t-ist. \\
\hline $\mathrm{C}$ & $0,010 * *$ & 2,1566 & $0,039 * * *$ & 4,2709 & $0,124 * *$ & 2,2616 \\
\hline DCCHINDİSTANABD $_{\mathrm{t}-1}$ & $-0,082 * * *$ & $-6,5938$ & $-0,101 * * *$ & $-7,295$ & $-0,144^{* * *}$ & $-6,942$ \\
\hline $\mathrm{RA}_{\mathrm{t}-1}^{+}$ & 0 & $-0,0286$ & $-0,019 *$ & $-1,6853$ & $0,062^{* *}$ & 2,1888 \\
\hline $\mathrm{RA}_{\mathrm{t}-1}^{-}$ & 0 & $-0,0272$ & $-0,019 *$ & $-1,686$ & $0,062 * *$ & 2,1915 \\
\hline  & 0,053 & 0,9719 & $-0,0596$ & $-1,1424$ & 0,0512 & 0,8643 \\
\hline$\triangle$ DCCHİNDİSTANABD $_{\mathrm{t}-2}$ & $-0,115^{* *}$ & $-2,2309$ & $-0,121 * * *$ & $-2,7208$ & $-0,236^{*}$ & $-1,8374$ \\
\hline$\triangle$ DCCHINDİSTANABDt-3 $_{\mathrm{t}}$ & 0,057 & 0,9382 & $-0,056$ & $-1,3651$ & $0,184 * * *$ & 3,284 \\
\hline$\triangle$ DCCHINDİSTANABD $_{\mathrm{t}-4}$ & $-0,065$ & $-1,5257$ & $-0,096^{* *}$ & $-2,0646$ & $-0,219 * * *$ & $-2,7577$ \\
\hline $\mathrm{DRA}_{\mathrm{t}}^{+}$ & $-0,001$ & $-0,1637$ & $-0,0008$ & $-0,1576$ & $-0,0053$ & $-0,7889$ \\
\hline DRA $_{t-1}^{+}$ & $0,086^{* * *}$ & 5,1002 & $0,101^{* * *}$ & 4,7313 & 0,0054 & 0,187 \\
\hline DRAt $^{+}{ }^{+}$ & $-0,017$ & $-1,3124$ & 0,0125 & 0,6988 & $-0,096 * * *$ & $-2,7396$ \\
\hline $\mathrm{DRA}_{\mathrm{t}-3}{ }^{+}$ & 0,018 & 1,4141 & 0,026 & 1,3225 & 0,0076 & 0,4169 \\
\hline $\mathrm{DRA}_{\mathrm{t}-4}{ }^{+}$ & $-0,040 * *$ & $-2,033$ & & & $-0,132 * * *$ & $-4,6844$ \\
\hline DRA $_{t}^{-}$ & $-0,005$ & $-0,3066$ & $-0,0021$ & $-0,1215$ & $-0,0215$ & $-0,9175$ \\
\hline $\mathrm{DRA}_{\mathrm{t}-1^{-}}$ & $-0,062 * * *$ & $-5,4142$ & $-0,051 * * *$ & $-4,2328$ & $-0,150 * * *$ & $-3,7721$ \\
\hline $\mathrm{DRA}_{\mathrm{t}-2^{-}}$ & $-0,015$ & $-0,9515$ & & & $-0,072 * *$ & $-2,3081$ \\
\hline $\mathrm{DRA}_{\mathrm{t}-3^{-}}$ & $-0,015$ & $-1,1408$ & & & $-0,110^{* * *}$ & $-2,9674$ \\
\hline $\mathrm{DRA}_{\mathrm{t}-4}{ }^{-}$ & 0,007 & 1,2798 & & & 0,025 & 1,0497 \\
\hline Düzeltilmiş $\mathrm{R}^{2}$ & \multicolumn{2}{|c|}{0,6031} & \multicolumn{2}{|c|}{0,5048} & \multicolumn{2}{|c|}{0,9042} \\
\hline \multicolumn{7}{|c|}{ Panel B: Asimetrik parametreler için uzun dönem katsayılar } \\
\hline RA+ & \multicolumn{2}{|c|}{0} & \multicolumn{2}{|c|}{$-0,19 *$} & \multicolumn{2}{|c|}{$0,43 * *$} \\
\hline $\mathrm{RA}^{-}$ & \multicolumn{2}{|c|}{0} & \multicolumn{2}{|c|}{$-0,19 *$} & \multicolumn{2}{|c|}{$0,43 * *$} \\
\hline
\end{tabular}

Not: $\triangle$ DCCHİNDİSTANABD'nin bağımlı değişken olduğu NARDL test sonuçları Tablo 9'da verilmiştir. Panel A, NARDL modelinin hata düzeltme gösterimi sonuçlarını göstermektedir . + ve - sırasıyla ilgili değişkenlerdeki pozitif ve negatif değişiklikleri göstermektedir. Panel B'de, ilgili değişkenlerin pozitif ve negatif değişimi ile ilişkili tahmini uzun-dönem katsayılar gösterilmiştir. ***,**** sırasıyla yüzde 1, yüzde 5, ve yüzde 10 seviyesinde anlamlılığı göstermektedir. 
Tablo 10. NARDL Test Sonuçları (Bağımlı Değişken: $\triangle$ DCCRUSYAABD)

\begin{tabular}{|c|c|c|c|c|c|c|}
\hline \multicolumn{7}{|l|}{ Panel A: Tahmini Katsayllar } \\
\hline \multirow[b]{2}{*}{ Bağımsız Değişkem } & \multicolumn{2}{|c|}{ Tüm örneklem dönemi } & \multicolumn{2}{|c|}{2008 krizi } & \multicolumn{2}{|c|}{ COVID-19 } \\
\hline & Katsay1 & t-ist. & Katsay 1 & t-ist. & Katsayı & t-ist. \\
\hline $\mathrm{C}$ & $0,019 * * *$ & 4,4431 & $0,063 * * *$ & 3,3066 & $0,294 * * *$ & 2,7277 \\
\hline DCCRUSYAABD $_{\mathrm{t}-1}$ & $-0,079 * * *$ & $-4,9462$ & $-0,064 * *$ & $-2,1279$ & $-0,145^{* * *}$ & $-5,5974$ \\
\hline $\mathrm{RA}_{\mathrm{t}-1}{ }^{+}$ & 0,011 & 0,7878 & $-0,0228$ & $-0,8747$ & $0,091^{* *}$ & 2,4972 \\
\hline $\mathrm{RA}_{\mathrm{t}-1^{-}}$ & 0,011 & 0,7895 & $-0,0228$ & $-0,8685$ & $0,092 * *$ & 2,5039 \\
\hline$\triangle$ DCCRUSYAABD $_{\mathrm{t}-1}$ & $-0,025$ & $-0,7381$ & $-0,0363$ & $-0,7851$ & $-0,252 * *$ & $-2,4652$ \\
\hline$\triangle$ DCCRUSYAABD $_{\mathrm{t}-2}$ & $-0,088$ & $-1,4832$ & $-0,0948$ & $-1,3337$ & $-0,316 * * *$ & $-2,9807$ \\
\hline$\triangle$ DCCRUSYAABD $_{\mathrm{t}-3}$ & 0,048 & 1,3641 & & & & \\
\hline \multicolumn{7}{|l|}{$\triangle$ DCCRUSYAABD $_{\mathrm{t}-4}$} \\
\hline $\mathrm{DRA}_{t}^{+}$ & 0,006 & 0,724 & $-0,0004$ & $-0,0349$ & 0,0137 & 0,8229 \\
\hline $\mathrm{DRA}_{\mathrm{t}-1}{ }^{+}$ & $0,089 * * *$ & 3,0724 & $0,140 * * *$ & 3,2195 & $0,058 * *$ & 2,081 \\
\hline DRAt-2 $^{+}$ & $-0,034 * * *$ & $-3,071$ & & & $-0,103 * *$ & $-2,5027$ \\
\hline DRA $_{t-3}{ }^{+}$ & 0,015 & 0,7329 & & & $0,093 * *$ & 2,2325 \\
\hline DRA $_{t-4}{ }^{+}$ & $-0,021$ & $-1,3857$ & & & $-0,084 * * *$ & $-2,7465$ \\
\hline $\mathrm{DRA}_{t}^{-}$ & $-0,002$ & $-0,0731$ & $-0,0023$ & $-0,0533$ & 0,0294 & 0,8841 \\
\hline $\mathrm{DRA}_{\mathrm{t}-1^{-}}$ & $-0,065 * * *$ & $-5,3002$ & $-0,065 * * *$ & $-5,8145$ & $-0,145 * * *$ & $-3,4222$ \\
\hline DRA $_{t-2^{-}}$ & 0,002 & 0,1109 & $-0,002$ & $-0,1096$ & $0,112 * * *$ & 2,8724 \\
\hline $\mathrm{DRA}_{t-3}{ }^{-}$ & $-0,019$ & $-1,5134$ & $-0,007$ & $-0,5679$ & $-0,0943$ & $-1,4793$ \\
\hline $\mathrm{DRA}_{\mathrm{t}-4^{-}}$ & 0,015 & 1,3097 & $0,023 * * *$ & 2,7117 & 0,0201 & 1,1264 \\
\hline Düzeltilmiş $\mathrm{R}^{2}$ & \multicolumn{2}{|c|}{0,3261} & \multicolumn{2}{|c|}{0,27} & \multicolumn{2}{|c|}{0,7564} \\
\hline \multicolumn{7}{|c|}{ Panel B: Asimetrik parametreler için uzun dönem katsayılar } \\
\hline RA+ & \multicolumn{2}{|c|}{0,14} & \multicolumn{2}{|c|}{$-0,36$} & \multicolumn{2}{|c|}{$0,63 * *$} \\
\hline $\mathrm{RA}^{-}$ & \multicolumn{2}{|c|}{0,14} & \multicolumn{2}{|c|}{$-0,36$} & \multicolumn{2}{|c|}{$0,63 * *$} \\
\hline
\end{tabular}

Not: $\triangle$ DCCRUSYAABD'nin bağımlı değişken olduğu NARDL test sonuçları Tablo 10'da verilmiştir. Panel A, NARDL modelinin hata düzeltme gösterimi sonuçlarını göstermektedir. + ve - sırasıyla ilgili değişkenlerdeki pozitif ve negatif değişiklikleri göstermektedir. Panel B'de, ilgili değişkenlerin pozitif ve negatif değişimi ile ilişkili tahmini uzun-dönem katsayılar gösterilmiştir. ***,**,* sırasıyla yüzde 1 , yüzde 5, ve yüzde 10 seviyesinde anlamlılığı göstermektedir.

Aynı Tablo 9'da belirtilen riskten kaçınma düzeyinin ABD ve Hindistan borsaları entegrasyonuna olan kısa vadeli etkileri, ABD ve Brezilya borsaları entegrasyonuna olan etkileriyle benzerlik göstermektedir. Her üç zaman aralığı için de riskten kaçınma düzeyindeki olumlu değişimler entegrasyonu genel olarak arttırırken, yatırımcıların riskten iştahının artması korelasyonu azaltmaktadır. Dahası bu etkilerin hepsinin asimetrik olduğu saptanmıştır. Bu sonuçlar, yatırımcıların BRIC pazarlarını çeşitlendirme ve risk azaltma seçeneği olarak algıladıkları görüşüne kanıt niteliğindedir (Mensi vd., 2016). Başka bir önemli bulgu, riskten kaçınma güzeyindeki değişikliklerin iki ülke arasındaki entegrasyona olan etkilerinin 2008 krizi sırasında ve COVID-19 esnasında büyüklük ve anlamlılık bakımından farklı sonuçlar vermesidir. Brzilya örneğinde olduğu gibi, Hindistan için de riskten kaçınma düzeyinin korelasyona etkisi pandemi döneminde 2008 krizine göre istatistiksle olarak daha anlamlı bulunmuş ve daha yüksek katsayılar elde edilmiştir. Dahası, düzeltilmiş $\mathrm{R}^{2}$ 'ler göz önüne alındığında, riskten kaçınma düzeyindeki değişikliklerin $\mathrm{ABD}$ 
ve Hindistan arasındaki korelasyonun COVID-19 döneminde \%90,42'sini açıklarken, 2008 krizinde sadece \%50,48'ini açıkladığı saptanmıştır. Bu bulgular, Demirer vd. (2018)'nin ileri sürdüğü nakit akışına bağlı olmayan faktörlerin bulaşma ve portföy riski modellerinde dikkate alınması gerektiği görüşünü desteklerken, bu faktörlerin kriz dönemlerinde de önemini sürdürdüğünü düşündürtmektedir. Bununla birlikte, riskten kaçış düzeyindeki değişikliklerin etkisinin COVID-19 döneminde 2008 krizine göre daha fazla olması, COVID-19'un bireylerin duyguları üzerinde daha fazla etki yarattığı ve davranış değişikliğine neden olduğunu, ve bu nedenle korku kaynaklı değiştiği savunulan riskten kaçınma düzeyinin etkisinin pandemi döneminde daha fazla olduğunu düşündürmektedir.

ABD ve Rusya borsa endeksleri arasındaki dinamik şartlı korelasyonuna riskten kaçınma düzeyindeki değişikliklerin etkileri tüm örneklem dönemi, 2008 krizi ve COVID-19 pandemi süreci için Tablo 10'da gösterilmiştir. Analizler, sadece COVID-19 döneminde riskten kaçınmadaki pozitif ve negatif değişikliklerin iki ülke arasındaki dinamik korelasyona anlamlı ve asimetrik bir etkisi olduğunu göstermektedir. Tablo 7'den da anlaş1lacağı gibi, Hindistan'a benzer şekilde Rusya için de riskten kaçınma düzeyindeki olumlu ve olumsuz değişiklikler entegrasyonu arttırmaktadır. Pandemi esnasında değişen riskten kaçınma düzeyi, Rusya ve ABD pazarlarını daha bütünleşmiş hale getirmiştir. Kısa vadede ise, riskten kaçınma düzeyindeki pozitif değişiklikler iki ülke arasındaki dinamik korelasyonu genellikle arttırırken, riskten kaçınma düzeyindeki düşüş entegrasyonu azaltmaktadır. Üstelik bu etkiler asimetriktir. Brezilya ve Hindistan örneğinde olduğu gibi, Rusya ve ABD arasindaki entegrasyon riskten kaçınma düzeyindeki değişikliklerden pandemi süresince daha fazla ve daha anlamlı şekilde etkilenmiştir. Bununla birlikte, düzeltilmiş $\mathrm{R}^{2}$ 'lere bakıldığında, riskten kaçınma düzeyindeki değişikliklerin $\mathrm{ABD}$ ve Rusya arasındaki entegrasyonu COVID-19 döneminde \%75,64 oranında açıklarken, 2008 krizinde sadece $\% 27$ oranında açıklamaktadır. $\mathrm{Bu}$ bulgu, Brezilya ve Hindistan örneklerinde olduğu gibi riskten kaçınmadaki zamansal değişimin birincil itici gücünün korku kaynaklı duygu temelli değişiklikler olduğu görüşünü desteklerken (Guiso vd., 2018:421), düzeltilmiş $\mathrm{R}^{2}$ 'lerin diğer iki ülkeye nazaran çok daha düşük olması, özellikle COVID-19 öncesi dönem için, Rusya ve ABD arasındaki dinamik korelasyonu açıklamakta nakit akışına bağlı olmayan faktörlerdeki değişikliklerden ziyade finansal faktörlerin daha etkili olduğu çıkarımının yapılmasına neden olmuştur.

Tablo 11. NARDL Test Sonuçları (Bağımlı Değişken: $\triangle$ DCCÇİNABD)

\begin{tabular}{|c|c|c|c|c|c|c|}
\hline \multicolumn{7}{|c|}{ Panel A: Tahmini Katsayılar } \\
\hline \multirow[b]{2}{*}{ Bağımsız Değişkem } & \multicolumn{2}{|c|}{ Tüm örneklem dönemi } & \multicolumn{2}{|c|}{2008 krizi } & \multicolumn{2}{|c|}{ COVID-19 } \\
\hline & Katsayı & t-ist. & Katsayı & t-ist. & Katsayı & t-ist. \\
\hline $\mathrm{C}$ & $0,003 * * *$ & 2,8532 & $0,004 * *$ & 2,0668 & 0,0097 & 0,4714 \\
\hline DCCÇİNABD $_{\mathrm{t}-1}$ & $-0,037 * * *$ & $-4,2171$ & $-0,059 * * *$ & $-3,0369$ & $-0,105 * * *$ & $-5,3648$ \\
\hline $\mathrm{RA}_{\mathrm{t}-1^{+}}$ & $-0,002 *$ & $-1,7562$ & $-0,0027$ & $-1,2476$ & 0,0086 & 1,2268 \\
\hline $\mathrm{RA}_{\mathrm{t}-1^{-}}$ & $-0,002^{*}$ & $-1,7573$ & $-0,0027$ & $-1,2571$ & 0,0087 & 1,2168 \\
\hline$\triangle \mathrm{DCCÇİNABD}_{\mathrm{t}-1}$ & 0,099 & 1,2645 & 0,0669 & 0,6954 & & \\
\hline$\triangle \mathrm{DCCÇINABD}_{\mathrm{t}-2}$ & 0,023 & 0,4325 & $-0,0847$ & $-1,2134$ & & \\
\hline$\triangle \mathrm{DCCÇİNABD}_{\mathrm{t}-3}$ & 0,027 & 0,9355 & & & & \\
\hline$\triangle \mathrm{DCCÇİNABD}_{\mathrm{t}-4}$ & & & & & & \\
\hline $\mathrm{DRA}_{\mathrm{t}}^{+}$ & 0,000 & $-0,0236$ & 0,0012 & 0,9714 & $-0,0009$ & $-0,393$ \\
\hline
\end{tabular}




\begin{tabular}{|c|c|c|c|c|c|c|}
\hline DRA $_{t-1}{ }^{+}$ & $0,012 * * *$ & 2,8525 & $0,008^{*}$ & 1,8249 & $0,019 * * *$ & 3,0105 \\
\hline DRA $_{t-2}{ }^{+}$ & 0,000 & 0,0069 & 0,0005 & 0,1526 & $-0,018^{* * *}$ & $-2,7143$ \\
\hline DRAAt-3 $^{+}$ & 0,004 & 1,4647 & $0,004 *$ & 1,6965 & $0,009 *$ & 1,9612 \\
\hline DRAAt-4 $^{+}$ & $-0,004^{*}$ & $-1,8658$ & & & $-0,016^{* * *}$ & $-3,2777$ \\
\hline DRA $_{t}^{-}$ & $-0,003$ & $-0,5761$ & $-0,0035$ & $-0,8462$ & $0,017 * *$ & 2,2653 \\
\hline $\mathrm{DRA}_{\mathrm{t}-1^{-}}$ & $-0,006^{* * *}$ & $-3,2556$ & $-0,006^{* *}$ & $-2,5152$ & $-0,022 * * *$ & $-3,3927$ \\
\hline $\mathrm{DRA}_{\mathrm{t}-2^{-}}$ & $-0,001$ & $-0,3406$ & 0,0016 & 0,8946 & 0,0038 & 0,5653 \\
\hline $\operatorname{DRA}_{t-3}{ }^{-}$ & $-0,001$ & $-0,2592$ & 0 & $-0,0077$ & $-0,021 * *$ & $-2,291$ \\
\hline $\operatorname{DRA}_{t-4^{-}}$ & $0,003^{* *}$ & 2,076 & 0,0018 & 1,607 & $0,009 * *$ & 2,5865 \\
\hline Düzeltilmiş $\mathrm{R}^{2}$ & \multicolumn{2}{|c|}{0,2276} & \multicolumn{2}{|c|}{0,2563} & \multicolumn{2}{|c|}{0,7437} \\
\hline \multicolumn{7}{|c|}{ Panel B: Asimetrik parametreler için uzun dönem katsayılar } \\
\hline $\mathrm{RA}^{+}$ & \multicolumn{2}{|c|}{$-0,05^{*}$} & \multicolumn{2}{|c|}{$-0,05$} & \multicolumn{2}{|c|}{0,08} \\
\hline $\mathrm{RA}^{-}$ & \multicolumn{2}{|c|}{$-0,05^{*}$} & \multicolumn{2}{|c|}{$-0,05$} & \multicolumn{2}{|c|}{0,08} \\
\hline
\end{tabular}

Not: $\triangle$ DCCÇİNABD'nin bağımlı değişken olduğu NARDL test sonuçları Tablo 11'de verilmiştir. Panel A, NARDL modelinin hata düzeltme gösterimi sonuçlarını göstermektedir. + ve - sırasıyla ilgili değişkenlerdeki pozitif ve negatif değişiklikleri göstermektedir. Panel B'de, ilgili değişkenlerin pozitif ve negatif değişimi ile ilişkili tahmini uzun-dönem katsayılar gösterilmiştir. ***,**** sırasıyla yüzde 1, yüzde 5, ve yüzde 10 seviyesinde anlamlılığı göstermektedir.

Çalışmada son olarak, riskten kaçınma düzeyindeki değişikliklerin Çin ve ABD borsaları arasındaki dinamik korelasyona uzun ve kısa dönem etkileri incelenmiş, ve sonuçlar Tablo 11'de verilmiştir. Diğer BRIC ülkelerinden farklı olarak, uzun dönemde, riskten kaçınma düzeyindeki pozitif ve negatif değişimlerin, Çin ve ABD borsaları arasındaki entegrasyona istatistiki olarak en az yüzde 5 düzeyinde anlamlı etkisi bulunamamıştır. $\mathrm{Bu}$ sonuç, yatırımcıların portföy çeşitlendirmelerinde Çin ve ABD piyasalarını eş zamanlı kullanmalarının, nakit akışına bağlı olmayan faktörlerden ziyade finansal faktörlerden etkilendiğini düşündürtmektedir. Kısa dönemde ise, kişilerin riskten kaçınma düzeyindeki azalış entegrasyonu azaltmaktadır. Dahası, riskten kaçınma düzeyindeki olumlu ve olumsuz değişimlerin kısa dönem etkisinin asimetrik olduğu Tablo 7'de gösterilmiştir. Öte yandan, tüm örneklem dönemi ve 2008 krizi için, riskten kaçınma düzeyindeki değiş̧imlerin Çin ve ABD piyasaları entegrasyonuna etkisi büyüklük ve anlamlılık açısından diğer BRIC ülkelerine kıyasla çok daha düşük olduğu gözlemlenmiştir. Özellikle 2008 krizi esnasında, yatırımların riskten kaçınma düzeyindeki artışların yüzde beş oranında anlamlı bir etkisi bulunamamıştır. Bu bulgular, Tablo 2'de ifade edilen Çin'in diğer BRIC piyasalarından ayrıştığı çıkarımını destekler niteliktedir. COVID-19 pandemi süresince ise, riskten kaçınma düzeyindeki değişimlerin iki ülke arasındaki korelasyona etkisi büyüklük ve anlamlılık olarak diğer BRIC ülkeleriyle benzeşmektedir. $\mathrm{Bu}$ bulgulardan, Çin ve $\mathrm{ABD}$ arasındaki entegrasyonun ekonomik kriz esnasında finansal faktörlerden etkilenirken, pandemi süresince nakit akışına bağlı olmayan faktör olan ve korkunun birincil itici gücü olan riskten kaçınma düzeyinden etkilendiği sonucu çıkarılabilmektedir (Guiso vd., 2018:421).

\section{TARTIŞMA VE SONUÇ}

Tüm dünyayı etkisi altına alan COVID-19 pandemisi, küresel ekonomi ve finans piyasalarını derinden etkilemiş ve hatta etkileri açısından 2008 krizini geride bırakmıştır (Choi, 2020:6). Bu çalışmanın amacı, yatırımcıların zamanla değişen riskten kaçınma düzeylerindeki değişimin, COVID-19 ve 2008 krizi dönemlerinde ABD ve BRIC ülkeleri hisse senedi piyasaları arasındaki dinamik korelasyona etkisini incelemektir. Ülkeler arası 
entegrasyonu bulmak için VAR(5)-DCC-GARCH(1,1) modelinden yararlanılırken, riskten kaçınma düzeyindeki olumlu ve olumsuz değişimlerin ülkelerin hisse senedi piyasalarının entegrasyonu açısından uzun ve kısa dönem asimetrik etkileri, gecikmesi dağıtılmış doğrusal olmayan otoregresif model (NARDL) yöntemiyle tahmin edilmiştir.

Ampirik bulgular, riskten kaçınma düzeyindeki değişimin ABD ile BRIC ülkeleri hisse senedi piyasaları arasındaki entegrasyona etkisinin hem ülkeler arası hem de kriz dönemlerinde kısmen heterojenlik sergilediğini göstermektedir. Uzun dönemde, 1 Ocak 200629 Ekim 2020 tarihlerini kapsayan örneklem döneminde riskte kaçınma düzeyindeki değişimin hiçbir ülke piyasası ve ABD piyasası arasındaki korelasyona anlamlı bir etkisi olduğu bulunmazken, kriz dönemlerinde Çin hariç diğer ülkeler ve ABD arasındaki entegrasyonu anlamlı şekilde etkilediği saptanmıştır. Kısa vadede ise, tüm ülkeler için riskten kaçınma düzeyindeki pozitif değişimlerin korelasyonu arttırdığı görülürken, negatif değişikliklerin korelasyonu azalttığ 1 belirtilmiştir. Üstelik bu etkiler tüm ülkeler ve tüm zaman aralıkları için asimetriktir. Bu bulgular, nakit akışına bağlı olmayan faktörlerin bulaşma ve portföy riski modelleri açısından önemini vurgulayan Demirer vd. (2018)'i destekler niteliktedir.

Çalışmanın bir diğer önemli katkısı, riskten kaçınma düzeyindeki değişimin ülkeler arasındaki entegrasyona etkisinin 2008 krizi ve pandemi süresince gösterdiği farklılığı gözler önüne sermesidir. Tüm BRIC piyasaları için, riskten kaçınma düzeyi pandemi sırasında 2008 krizine göre ülkeler arası korelasyonu çok daha fazla ve anlamlı bir şekilde etkilemektedir. Hatta salgın süresince, Brezilya ve Hindistan ile ABD arasındaki entegrasyonu neredeyse tek başına açıklamaktadır. Bu açıdan çalışma, COVID-19 pandemisinin etkilerinin 2008 krizinin yarattığından daha fazla olduğunu ileri süren Choi (2020)'yi destekler niteliktedir. Aynı zamanda, bireylerin bir doğal afet yaşadıktan sonra daha fazla riskten kaçındığını gösteren literatürle de örtüşmektedir (bkz. Kim ve Lee, 2014; Cameron ve Shah, 2015). COVID-19 döneminde riskten kaçış düzeyindeki değişikliklerin etkisinin 2008 krizindeki etkisine göre daha fazla olması, zamanla riskten kaçınmada meydana gelen değişimin asli itici gücünün servet veya beklenen gelirdeki değişiklikler değil korkudan kaynaklı duygu temelli değişiklikler olduğu görüşünü de desteklemektedir (Guiso vd., 2018:421).

Son olarak çalışmada, riskten kaçınma düzeyindeki değişimlerin ülkeler arasındaki entegrasyona etkisinin Rusya ve Çin için diğer BRIC ülke piyasalarına göre büyüklük ve anlamlılık olarak çok daha düşük olduğu görülmüştür. Bilhassa pandemi öncesi dönem için, Rusya ve Çin ile ABD arasındaki dinamik korelasyonu açıklamakta riskten kaçınma düzeyindeki değişikliklerden ziyade finansal faktörlerin daha etkili olduğu çıkarımı yapılmıştır. Bu iki ülke ve ABD arasındaki entegrasyona korku temelli olan riskten kaçınma düzeyinin etkisinin 2008 krizinden ziyade pandemi süresince daha fazla olması, salgın dönemlerinde bireylerin yatırım davranışlarının duygu temelli değişkenlerden, ekonomik kriz dönemine göre daha fazla etkilendiğini düşündürtmektedir.

Çalışmanın bulguları, nakit akışına bağlı olmayan risk faktörlerinin ülkeler arasındaki entegrasyona etkisinin önemini gözler önüne sererken, COVID-19 pandemisi süresince riskten kaçınma düzeyindeki değişikliğin etkisinin 2008 krizine göre çok daha fazla olduğunu göstermektedir. Riskten kaçınma düzeyinin değişmesinin korkudan kaynaklı olduğu görüşü gözönüne alındığı zaman, bireylerin artan korkudan kaynaklı portföylerini çeşitlendirme isteklerinin pandemi döneminde 2008 krizi dönemine göre daha fazla olduğu sonucuna 
ulaşılmıştır. $\mathrm{Bu}$ çalışma, özellikle küresel salgın veya ekonomik kriz dönemlerinde $\mathrm{ABD}$ ve BRIC ülke piyasalarına yatırım yaparak portföy çeşitlendirme firsatı arayan yatırımcılar için ve gelişmekte olan ülkelerdeki politika yapıcıları için önemli çıktılar sunmaktadır. Son olarak, riskten kaçınma düzeyindeki değişikliklerin etkisi ile ilgili piyasalar arasında karşılaştırma yapabilmek için, riskten kaçınmanın gelişmiş ve geliş̧mekte olan diğer ülke piyasalarının entegrasyonlarına kriz ve pandemi dönemlerindeki etkisinin incelenmesine ihtiyaç vardır.

\section{KAYNAKLAR}

Allen, Franklin - Gale, Douglas (2001), “Financial Contagion”, Journal of Political Economy, 108, pp.1-33.

Aloui, Riadh- Aissa, Mohamed Safouane F.- Nguyen, Duc Khuong (2011), “Global Financial Crisis Extreme Interdependences and Contagion Effects: The Role of Economic Structure?”, Journal of Banking and Finance, 35, pp.130-141.

Azimli, Asil (2020), "The Impact of COVID-19 on the Degree of Dependence and Structure of Risk-Return Relationship: A Quantile Regression Approach”, Finance Research Letters, 36, pp.1-13.

Baker, Scott R.- Bloom, Nicholas- Davis, Steven J.- Kost, Kyle J.- Sammon, Marco C.Viratyosin, Tasaneeya (2020), "The Unprecedented Stock Market Impact of Covid19”, National Bureau of Economic Research Working paper No. w26945.

Bekiros, Stelios D. (2013), "Contagion, Decoupling and the Spillover Effects of the US Financial Crisis: Evidence from the BRIC Markets”, International Review of Financial Analysis, 33, pp.58-69.

Bekaert, Geert- Engstrom, Eric- Xu, Nancy R. (2019), "The Time Variation in Risk Appetite and Uncertainty", National Bureau of Economic Research Working Paper, No. w25673.

Berger, Dave-Turtle, H. J. (2011), “Emerging Market Crises and US Equity Market Returns”, Global Finance Journal, 22, pp.32-41.

Broner, Fernando A.- Gelos, R.Gaston- Reinhart, Carmen M. (2006) "When in Peril, Retrench: Testing the Portfolio Channel of Contagion", Journal of International Economics, 69, pp.203-230.

Cameron, Lisa- Shah, Manisha (2015), "Risk-Taking Behavior in The Wake of Natural Disasters”, Journal of Human Resources, 50, pp.484-515.

Chen, Mei-Ping- Lee, Chien C.- Lin, Yu H.- Chen, Wen Y. (2018), "Did the SARS Epidemic Weaken the Integration of Asian Stock Markets? Evidence from Smooth TimeVarying Cointegration Analysis”, Economic Research, 31, pp.908-926.

Choi, Sun-Yong (2020), "Industry Volatility and Economic Uncertainty Due to the COVID19 Pandemic: Evidence From Wavelet Coherence Analysis”, Finance Research Letters, 37, pp.1-8. 
Corbet, Shaen- Hou, Yang- Hu, Yang- Oxley, Les- Xu, Danyang (2021), "Pandemic-related Financial Market Volatility Spillovers: Evidence from Chinese COVID-19 epicentre”, International Review of Economics and Finance, 71, pp.55-81.

Dakhlaoui, Imen- Aloui, Chaker (2016), “The Interactive Relationship between the US Economic Policy Uncertainty and BRIC’ Stock Markets”, International Economics, 146, pp.141-157.

Demirer, Riza- Omay, Tolga- Yuksel Asl1- Yuksel, Aydın (2018), “Global Risk Aversion and Emerging Market Return Comovements”, Economics Letters, 173, pp.118-121.

Dickey, A. David- Fuller, Wayne A. (1979), "Distribution of the Estimators for Autoregressive Time Series with a Unit Root”, Journal of the American Statistical Association, 74, pp.427-431.

Didier, Titiana- Hevia, Constantino- Schmukler, Sergio L. (2012), "How Resilient and Countercyclical were Emerging Economies during the Global Financial Crisis?”, Journal of International Money and Finance, 31, pp.2052-2077.

Dimitriou, Dimitrios- Kenourgios, Dimitris- Simos, Theodore (2013), “Global Financial Crises and Emerging Stock Market Contagion: A Multivariate FIAPARCH-DCC Approach”, International Review of Financial Analysis, 30, pp.46-56.

Engle, Robert F. (1982), “Autoregressive Conditional Heteroskedasticity with Estimates of the Variance of United Kingdom Inflation”, Econometrica, 50, pp.987-1007.

Engle, Robert F. (2002), “Dynamic Conditional Correlation- a Simple Class of Multivariate GARCH Models”, Journal of Business and Economic Statistics, 20, pp.339-50.

Forbes, Kristin- Chinn, Menzie (2004), “A Decomposition of Global Linkages in Financial Markets Over Time”, The Review of Economics and Statistics, 86, pp.705-722.

Forbes, Kristin- Rigobon, Roberto (2002), “No Contagion, Only Interdependence: Measuring Stock Market Co-movements”, The Journal of Finance, 57, pp.2223-2261.

Guiso, Luigo- Sapienza, Paola- Zingales, Luigo (2018), “Time Varying Risk Aversion”, Journal of Financial Economics, 128, pp.403-421.

Harvey, Campbell (2020), “The Economic and Financial Implications of COVID-19”, (3rd April, 2020), https://www.darden.virginia.edu/mayo-center/events/virtualspeakerseries.

Kenourgios, Dimitris- Samitas, Aristeidis - Paltalidis, Nikos (2011), "Financial Crises and Stock Market Contagion in a Multivariate Time-Varying Asymmetric Framework", Journal of International Financial Markets Institutions and Money, 21, pp.92-106.

Kim, Yong I.- Lee, Jungmin (2014), “The Long-run Impact of a Traumatic Experience on Risk Aversion”, Journal of Economic Behavior Organization, 108, pp.174-186. 
Knutson, Brain- Wimmer, Elliot- Kuhnen, Camelia- Winkielman, Piotr (2008), "Nucleus Accumbens Activation Mediates the Influence of Reward Cues on Financial Risk Taking”, NeuroReport, 19, pp.509-513.

Kocaarslan, Barış- Soytas, Uğur- Sarı, Ramazan- Ugurlu, Ecenur (2018), “The Changing Role of Financial Stress, Oil Price, and Gold Price in Financial Contagion among US and BRIC Markets”, International Reviews of Finance, 19, pp.541-574.

Loewenstein, George (2000), "Emotions in Economic Theory and Economic Behavior”, American Economic Review, 90,pp.426-432.

Longin, François- Solnik, Bruno (2001), "Extreme Correlation of International Equity Market”, The Journal of Finance, 56, pp.649-676.

Masson, Paul (1999), “Contagion: Macroeconomic Models with Multiple Equilibria”, Journal of International Money and Finance, 18, pp.587-602.

Mensi, Walid- Hammoudeh, Shawkat- Nguyen, Duc K.- Hoon, Sang (2016), "Global Financial Crisis and Spillover Effects among the U.S. and BRICS Stock Markets”, International Review of Economics and Finance, 42, pp.257-276.

Miranda-Agrippino- Silvia- Rey, Helena (2015), "World Asset Markets and the Global Financial Cycle”, NBER Working Paper: 21722.

Rey, Helene (2018), "Dilemma not Trilemma: The Global Financial Cycle and Monetary Policy Independence”, NBER Working Paper: 21162.

Pesaran, M.Hashem- Shin, Yongcheol (1998), “An Autoregressive Distributed-lag Modelling Approach to Cointegration Analysis”, Economic Soc. Monogr, 31, pp.371-413.

Phillips, Peter C.B.- Perron, Pierre (1988), "Testing for a Unit Root in Time Series Regression”, Biometrika, 75, pp.335-346.

Shin, Yongcheol- Yu, Byungchul- Greenwood-Nimmo, Matthew (2014), "Modelling Asymmetric Cointegration and Dynamic Multipliers in a Nonlinear ARDL Framework”, Springer, New York, NY, pp.281-314.

Tsai, I-Chun (2014), "Spillover of Fear: Evidence from the Stock Markets of Five Developed Countries”, International Review of Financial Analysis, 33, pp.281-288.

Uğurlu-Yıldırım, Ecenur (2020), "The Impact of COVID-19 Pandemic on the Financial Contagion among Turkey, US, and China Stock Markets”, Journal of Business Research-Turk, 12, pp.2764-2773.

Werner, Jan (2008), “Risk Aversion”, The New Palgrave Dictionary of Economics, pp.1-6.

Xu, Nancy R. (2019), “Global Risk Aversion and International Return Comovements”, Available at SSRN: https://ssrn.com/abstract=3174176. 